\title{
A SIMPLEST SYSTEMATICS FOR THE ORGANIZATION OF TURN-TAKING FOR CONVERSATION
}

\author{
HARVEY SACKS \\ University of California, \\ Irvine
}

\author{
EMANuel A. SchEGLOFF \\ University of California, \\ Los Angeles
}

\author{
GAIL JEFFERSON \\ University of Pennsylvania
}

The organization of taking turns to talk is fundamental to conversation, as well as to other speech-exchange systems. A model for the turn-taking organization for conversation is proposed, and is examined for its compatibility with a list of grossly observable facts about conversation. The results of the examination suggest that, at least, a model for turn-taking in conversation will be characterized as locally managed, party-administered, interactionally controlled, and sensitive to recipient design. Several general consequences of the model are explicated, and contrasts are sketched with turn-taking organizations for other speech-exchange systems.*

1. INTRODUCTION. Turn-taking is used for the ordering of moves in games, for allocating political office, for regulating traffic at intersections, for serving customers at business establishments, and for talking in interviews, meetings, debates, ceremonies, conversations etc. - these last being members of the set which we shall refer to as 'speech exchange systems'. It is obviously a prominent type of social organization, one whose instances are implicated in a wide range of other activities. For socially organized activities, the presence of 'turns' suggests an economy, with turns for something being valued —and with means for allocating them, which affect their relative distribution, as in economies. An investigator interested in the sociology of a turn-organized activity will want to determine, at least, the shape of the turn-taking organization device, and how it affects the distribution of turns for the activities on which it operates.

For the investigator of turn-taking systems per se, it is not surprising that turntaking systems can be workably built in various ways. Since they are used to organize sorts of activities that are quite different from one another, it is of particular interest to see how operating turn-taking systems are characterizable as adapting to properties of the sorts of activities in which they operate. Again, an investigator interested in some sort of activity that is organized by a turn-taking system will want to determine how the sort of activity investigated is adapted to, or constrained by, the particular form of turn-taking system which operates on it.

The subject of this report is the turn-taking system for conversation, and the foregoing are among the questions to which it will be addressed. Others have noted that the organization of taking turns at talk is one type of organization operative in conversation, and have located a range of interesting features and details of that sort of organization. ${ }^{1}$ But no account of the systematics of the organization of

* An earlier version of this paper was presented at the Conference on the Sociology of Language and Theory of Speech Acts, Bielefeld, Germany, April 1973.

${ }^{1}$ For example, Goffman 1955, 1964, 1971; Albert 1964; Kendon 1967; Yngve 1970; Duncan 1972a,b, 1973. Thus Goffman (1964:135-6):

Card games, ball-room couplings, surgical teams in operation, and fist fights provide examples of encounters; all illustrate the social organization of shared current orientation, and all involve an organized interplay of acts of some kind. I want to suggest that when 
turn-taking for conversation is yet available. Here, on the basis of research using audio recordings of naturally occurring conversations, we attempt to characterize, in its simplest systematic form, the organization of turn-taking for conversation, and to extract some of the interest of that organization.

Aspects of the organization we call turn-taking have forced themselves on investigators of 'small-group' behavior-who, in dealing with problems concerning the distribution of talk among participants in small groups, ${ }^{2}$ or the kinds of 'acts' which form sequences in small-group sessions, ${ }^{3}$ have encountered problems conditioned in central ways by the turn-taking system, though for the most part they have not addressed them in this light. Again, students of 'interview' behavior, and such two-party conversation as approximates it in form, ${ }^{4}$ have concerned themselves with the distribution of talk among the parties, the distribution of silences, the sequences in which the talk shifted from one to another or was retained by a single party, and the way such transfer or retention was coördinated. These workers have also dealt with questions on which turn-taking has a central bearing; but they attacked them only peripherally in turn-taking terms, or accounted for them unsatisfactorily because of weaknesses in the turn-taking models explicitly or implicitly employed. In anthropology, some investigators have explicitly noted aspects of turn organization; ${ }^{5}$ but their observations have been, for the most part,

speaking occurs it does so within this kind of social arrangement; of course what is organized therein is not plays or steps or procedures or blows, but turns at talking. Note then that the natural home of speech is one in which speech is not always present.

I am suggesting that the act of speaking must always be referred to the state of talk that is sustained through the particular turn at talking, and that this state of talk involves a circle of others ratified as coparticipants. (Such a phenomenon as talking to oneself, or talking to unratified recipients as in the case of collusive communication, or telephone talk, must first be seen as a departure from the norm, else its structure and significance will be lost.) Talk is socially organized, not merely in terms of who speaks to whom in what language, but as a little system of mutually ratified and ritually governed face-to-face action, a social encounter. Once a state of talk has been ratified, cues must be available for requesting the floor and giving it up, for informing the speaker as to the stability of the focus of attention he is receiving. Intimate collaboration must be sustained to ensure that one turn at talking neither overlaps the previous one too much, nor wants for inoffensive conversational supply, for someone's turn must always and exclusively be in progress.

${ }^{2}$ E.g. Stephan \& Mishler 1952; Bales 1950, 1970; Coleman 1960.

${ }^{3}$ Cf. Bales 1950.

${ }^{4}$ Cf. Jaffe \& Feldstein 1970, Matarazzo \& Wiens 1972.

${ }^{5}$ E.g., Mitchell (1956:79) says:

Important headmen also have the right of walking in front of their juniors. If there are three or four headmen returning from, say, a court case, they arrange themselves in the pathway in an order which reflects their rank. As they file down the narrow field paths the leader is the most senior among the group. After him come the other headmen and last of all the commoners. This order of precedence is also followed when initiands pass through the tribal initiation ceremonies.

Or, to quote Beardsley et al. (1959:88):

Father and mother take the small children in to bathe with them, granny scrubs the men's backs, and relatives or neighbors who have no bath (three houses in Niiike) come to chat while waiting their turn at the end of the day. The senior male of the household finishes his bath first and the family follows in regular order of sex and age precedence. The first bather gets the hottest water. 
in the service of other interests-e.g., stratification, the legal system, etc.-and little effort has been directed at either gathering or attending materials in sufficient detail to permit appreciation or treatment of turn-taking as a central phenomenon in its own right. ${ }^{6}$ In all these domains of inquiry, what has attracted investigators' attention has been some particular outcome or product of the operation of turntaking, interpretably relevant to some other problem-but not the organization and operation of the system that allowed or produced such an outcome. Those approaches which have addressed turn-taking head-on, with proper appreciation of the depth of its implications and the detailed character of its organization, have been largely programmatic or only beginningly empirical; in any case, no systematic account is available. ${ }^{7}$

For the last half dozen years we have been engaged in research, using tape recordings of natural conversation, that has been increasingly directed to extracting, characterizing, and describing the interrelationships of the various types of sequential organization operative in conversation. The disciplinary motivation for such work is sociological. Our concern with the organization of turn-taking has the

Earlier, Isaacs (1933:222-3), a psychologist doing what amounted to an ethnography of children, wrote:

'Taking turns' is one of the hardest lessons for children under five years to learn ... the young child cannot without much experience believe that 'his turn' really will come in due time. All that he knows is that the others 'have got it' and he hasn't. A few minutes is an eternity when one is eagerly waiting for a prized pleasure such as riding on a tricycle or a see-saw. Nor does one believe in the goodwill of the others who are enjoying their turns first-one knows only too well how readily one would exclude THEM if one were allowed! Only the proved evenness of justice of the controlling adult will make a transition possible from the impetuous assertion of 'I want it Now' to that trust in the future which makes 'taking turns' possible.

${ }^{6}$ Among anthropologists, Albert (1964:40-41) has come the closest to addressing turn-taking per se:

The order in which individuals speak in a group is strictly determined by seniority of rank. If the eldest present is lower in social rank than some other individual, age gives way before social status. Thus, a nephew may be older than his uncle, but the uncle is of higher rank and will speak before him. A prince or chief may be younger than others present, but speaks first by virtue of his higher rank. There are no recorded instances of confusion or conflict in the matter of determining order of precedence, even in very large groups.

In public, the rule for servants, females, and other inferiors is to speak when spoken to but otherwise to maintain silence. Nevertheless, the pattern is so arranged that younger or socially inferior persons are in due course able to express their views. Thus, the senior person will speak first; the next in order of rank opens his speech with a statement to the effect, 'Yes, I agree with the previous speaker, he is correct, he is older, and knows best, etc.' Then, depending on circumstances and issues, the second speaker will by degrees or at once express his own views, and these may well be diametrically opposed to those previously expressed. No umbrage is taken, the required formula of acknowledgement of the superior having been used. If the umukuru, senior person, is truly very aged and weak, his son may speak first, explaining his departure from the rules at the outset; 'My father is old, his memory is not good, he wishes me to speak for him,' or some other appropriate excuse is given. It is not unusual for the formal order of precedence to be abandoned in the latter part of a protracted discussion, and for loud voices to be heard even among upper-class individuals.

${ }^{7}$ Except, perhaps, for Samuel Beckett's The lost ones (1972). 
following base. First, the existence of organized turn-taking is something that the data of conversation have made increasingly plain. It has become obvious that, overwhelmingly, one party talks at a time, though speakers change, and though the size of turns and ordering of turns vary; that transitions are finely coördinated; that techniques are used for allocating turns, whose characterization would be part of any model for describing some turn-taking materials; and that there are techniques for the construction of utterances relevant to their turn status, which bear on the coördination of transfer and on the allocation of speakership. In short, a body of factual material, accessible to rather unmotivated inquiry, exposes the presence of turn-taking and the major facets of its organization. Focusing on facts such as these, rather than on particular outcomes in particular settings, leads to an investigation of the organization of turn-taking per se, rather than to its application and consequences in particular contexts, although the more formal understanding of turn-taking illuminates more particular findings.

Second, we have found reasons to take seriously the possibility that a characterization of turn-taking organization for conversation could be developed which would have the important twin features of being context-free and capable of extraordinary context-sensitivity. ${ }^{8}$ We look for such a type of organization for the following reasons. To begin with, a problem for research on actual conversation is that it is always 'situated'-always comes out of, and is part of, some real sets of circumstances of its participants. But there are various reasons why it is undesirable to have to know or characterize such situations for particular conversations in order to investigate them. And the question then becomes: What might be extracted as ordered phenomena from our conversational materials which would not turn out to require reference to one or another aspect of situatedness, identities, particularities of content or context?

One reason for expecting the existence of some such type of organization is as follows. Conversation can accommodate a wide range of situations, interactions in which persons in varieties (or varieties of groups) of identities are operating; it can be sensitive to the various combinations; and it can be capable of dealing with a change of situation within a situation. Hence there must be some formal apparatus which is itself context-free, in such ways that it can, in local instances of its operation, be sensitive to and exhibit its sensitivity to various parameters of social

${ }^{8}$ When we speak of 'context-free' and 'context-sensitive,' we cannot state the scope of reference of 'context' that is relevant. For now, let it suffice to employ a long-term understanding of 'context' in the social sciences-one which attends the various places, times, and identities of parties to interaction. What we mean to note is that major aspects of the organization of turn-taking are insensitive to such parameters of context, and are, in that sense, 'contextfree'; but it remains the case that examination of any particular materials will display the context-free resources of the turn-taking system to be employed, disposed in ways fitted to particulars of context. It is the context-free structure which defines how and where contextsensitivity can be displayed; the particularities of context are exhibited in systematically organized ways and places, and those are shaped by the context-free organization.

We understand that linguists use a different sense of 'context-free' and 'context-sensitive', in which 'context' refers to syntactic or phonological environment, so that 'context-free' and 'context-sensitive' are mutually exclusive possibilities. Our usage goes, in the first instance, to social contexts; whether it has a bearing on phonological or syntactic ones we cannot say. 
reality in a local context. Some aspects of the organization of conversation must be expected to have this context-free, context-sensitive status; for, of course, conversation is a vehicle for interaction between parties with any potential identities, and with any potential familiarity. We have concluded that the organization of TURN-TAKING for conversation might be such a thing. That is, it appears to have an appropriate sort of general abstractness and local particularization potential.

In sum, turn-taking seems a basic form of organization for conversation'basic', in that it would be invariant to parties, such that whatever variations the parties brought to bear in the conversation would be accommodated without change in the system, and such that it could be selectively and locally affected by social aspects of context. Depiction of an organization for turn-taking should fit the facts of variability by virtue of a design allowing it to be context-sensitive; but it should be cast in a manner that, requiring no reference to any particular context, still captures the most important general properties of conversation.

To merit serious consideration, it seems to us, a model should be capable of accommodating (i.e. either be compatible with, or allow the derivation of) the following grossly apparent facts. ${ }^{9}$ In any conversation, we observe the following: ${ }^{10}$

(1) Speaker-change recurs, or at least occurs (cf. $\$ 4.1$, below).

(2) Overwhelmingly, one party talks at a time (cf. $\$ 4.2$ ).

(3) Occurrences of more than one speaker at a time are common, but brief (cf. §4.3).

(4) Transitions (from one turn to a next) with no gap and no overlap are

\footnotetext{
${ }^{9}$ There are obvious structures involved in this list: historical structures, by reference to which some facts would be noted only after others; and substantive structures, in which different points are variously related to each other. The list is presented so as to over-ride any such structures. Much might be learned from considering them, but we are not interested here in such uses of these points. The list of points is intended as a set of empirical constraints on the model we propose, and, for now, nothing more-just as most of the attention we will give our model of turn-taking will be addressed to showing that the model meets the constraints set by these empirical observations. The list should be read with these intended uses in mind. For example, each item might be read as following not the item that preceded it in the list, but following the sentence preceding the list as a whole.

${ }^{10}$ The heading 'in any conversation' has raised, for several readers of this paper in manuscript, the question of cross-cultural validity. Such a question can, of course, be settled only empirically, by examining varieties of conversational materials. We can report the validity of our assertions for the materials we have examined, and apparently for Thai materials examined by Moerman 1972, New Guinea creole materials examined by G. Sankoff (personal communication), and for an undetermined number of languages in the competence of a substantial number of linguists (at the Linguistic Institute in Ann Arbor, Summer 1973, and elsewhere) who have found what follows to be consistent with what they know of their languages, or illuminating of otherwise recalcitrant problems in their understanding. Furthermore, examination of cross-cultural conversation, where parties do not share a language of competence but a lingua franca in which all are only barely competent, is consistent with what follows (cf. Jordan \& Fuller, Ms). Finally, the cross-cultural question, as we understand it, asks how the structures on which we report vary across languages (lexically or syntactically conceived), or language communities, or across social organizations etc.- -structures which are thereby cast as more basic ones. That ordering is not at all clear to us. We do find that aspects of turntaking organization may vary in terms of other aspects of the sequential organization of conversation. And, as we suggest in the final section of this paper, there are various turn-taking systems for various speech-exchange systems, e.g. conversation, debate etc.
} 
common. Together with transitions characterized by slight gap or slight overlap, they make up the vast majority of transitions (cf. \$4.4).

(5) Turn order is not fixed, but varies (cf. §4.5).

(6) Turn size is not fixed, but varies (cf. \$4.6).

(7) Length of conversation is not specified in advance (cf. §4.7).

(8) What parties say is not specified in advance (cf. \$4.8).

(9) Relative distribution of turns is not specified in advance (cf. §4.9).

(10) Number of parties can vary (cf. §4.10).

(11) Talk can be continuous or discontinuous (cf. $\$ 4.11$ ).

(12) Turn-allocation techniques are obviously used. A current speaker may select a next speaker (as when he addresses a question to another party); or parties may self-select in starting to talk (cf. §4.12).

(13) Various 'turn-constructional units' are employed; e.g., turns can be projectedly 'one word long', or they can be sentential in length (cf. §4.13).

(14) Repair mechanisms exist for dealing with turn-taking errors and violations; e.g., if two parties find themselves talking at the same time, one of them will stop prematurely, thus repairing the trouble (cf. \$4.14).

To at least expose the interest of this area, we shall here offer and consider a simplest systematics for the organization of turn-taking in conversation, which does come to terms with the above list. ${ }^{11}$ We shall then proceed to show how it deals with the obvious facts and with others that are rather less obvious. Thereafter we will consider its structure and import. With regard to its import, we offer two comments now on the potential interest of such a model:

(a) When facts like those listed above are compared with those which obtain for various of the other speech-exchange systems (e.g. meetings, interviews, debates, or ceremonies), differences are readily noted. The size of turns and the ordering of turns in debates, for example, are obviously pre-specified. Those differences suggest that different turn-taking systems are involved. Conversation obviously occupies a central position among the speech-exchange systems; perhaps its turn-taking system is more or less explanatory of that centrality.

(b) Turns are valued, sought, or avoided. The social organization of turn-taking distributes turns among parties. It must, at least partially, be shaped as an economy. As such, it is expectable that, like other economies, its organization will affect the relative distribution of that which it organizes. Until we unravel its organization, we shall not know what those effects consist of, and where they will turn up. But, since

\footnotetext{
${ }^{11}$ Other gross empirical features of conversation could be added to our list. The ones we have noted are all important aspects of the organization of turn-taking for conversation, and are therefore critical tests of a model of that organization. Space considerations preclude developing for each point the ways in which it is critical. One evidence of the crucial character of at least some of the points is that, when other than the observed feature is the case, the turn-taking system that it becomes correct for is not one for CONVERSATION, but for some other speechexchange system. In that sense, any such feature (e.g. the non-prespecification of turn-order or turn-size) is criterial for the organization of turn-taking for conversation, and it is critical that a proposed model be compatible with it.
} 
all sorts of scientific and applied research use conversation now, they all employ an instrument whose effects are not known. This is perhaps unnecessary.

2. THE TRANSCRIPTS. Before proceeding to the systematics for turn-taking in conversation, the reader is urged to examine the Appendix, in which the special symbols used in the transcript are explained.

3. A SIMPLEST SYSTEMATICS. The turn-taking system for conversation can be described in terms of two components and a set of rules, as follows.

3.1. THE TURN-CONSTRUCTIONAL COMPONENT. There are various unit-types with which a speaker may set out to construct a turn. Unit-types for English include sentential, clausal, phrasal, and lexical constructions (cf. $\S 4.13$ below). Instances of the unit-types so usable allow a projection of the unit-type under way, and what, roughly, it will take for an instance of that unit-type to be completed. Unit-types lacking the feature of projectability may not be usable in the same way. ${ }^{12}$

12 We may note that it is empirically evident, from sequential materials, that projectability is the case; i.e., we find sequentially appropriate starts by next speakers after turns composed of single-word, single-phrase, or single-clause constructions, with no gap-i.e. with no waiting for possible sentence completion. Here are examples of single-word turns.

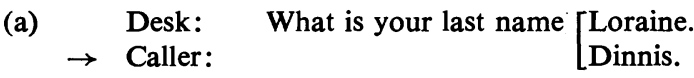

$\rightarrow$ Desk: What?

$\rightarrow$ Caller: Dinnis.

[FD:IV:191]

(b) Jeanette: Oh you know, Mittie- Gordon, eh- Gordon, Mittie's husband died. $(0.3)$

Estelle: Oh whe::n.

Jeanette: Well it was in the paper this morning.

Estelle: It wa::s,

$\rightarrow$ Jeanette: Yeah.

(c) Fern: Well they're not comin',

$\rightarrow$ Lana: Who.

Fern: Uh Pam, unless they c'n find somebody.

[Trio:18]

[Ladies: $3: 2: 5]$

(d) Guy: Is Rol down by any chance dju know?

$\rightarrow$ Eddy: $\overline{\text { Huh }}$ ?

Guy: $\quad$ Is uh Smith down?

Eddy: Yeah he's down,

[NB:I:5:4]

Examples of single-phrase turns:

(e) A: Oh I have the- I have one class in the e:vening.

$\rightarrow$ B: $\quad$ On Mondays?

A: $\quad$ Y- $\overline{\mathrm{uh}}:::$ Wednesdays. $=$

B: $\quad=$ Uh- Wednesday, $=$

A: =En it's like a Mickey Mouse course. [TG:6]

(f) Anna: Was last night the first time you met Missiz Kelly?

$\rightarrow$ Bea: $\quad$ Met whom?

Anna: Missiz Kelly.

Bea: $\quad$ Yes.

[Ladies:2:8:5] 
As for the unit-types which a speaker employs in starting the construction of a turn's talk, the speaker is initially entitled, in having a turn, to one such unit. The first possible completion of a first such unit constitutes an initial transition-relevance place. Transfer of speakership is coördinated by reference to such transitionrelevance places, which any unit-type instance will reach.

3.2. TURN-ALlOCATION COMPONENT. Turn-allocational techniques are distributed into two groups: (a) those in which next turn is allocated by current speaker's selecting next speaker; and (b) those in which a next turn is allocated by self-selection. ${ }^{13}$

Examples of single-clause turns:

(g) A: Uh you been down here before $\left[\begin{array}{l}\text { havenche. } \\ \text { Yeh. }\end{array}\right.$

$\begin{aligned} \rightarrow \text { A: } & \text { Where the sidewalk is? } \\ \text { B: } & \text { Yeah, } \\ \rightarrow \text { A: } & \text { Whur it ends, } \\ \text { B: } & \text { Goes [all a' way up there? } \\ \text { A: } & \\ \text { A: } & \text { Yeah }\end{aligned}$

[NB:III:3]

For another sort of evidence on this point, see $\$ 4.13$ below and examples 24-27. For additional data and discussion of the precise placement of talk starts, cf. Jefferson 1973. How projection of unit-types is accomplished, so as to allow such 'no gap' starts by next speakers, is an important question on which linguists can make major contributions Our characterization in the rules, and in the subsequent disccussion, leaves open the matter of how projection is done.

${ }^{13}$ An example is:
(a) Sara: Ben you want some $(\quad)$ ?
Ben: Well allright I'll have a,
((pause))
Sara: Bill you want some?
Bill: $\quad$ No,

[Schenkein:II:49]

Here Ben and Bill's turns are allocated by Sara (instances of current-Sara-selecting next), and Sara's turns are by self-selection. Another example:

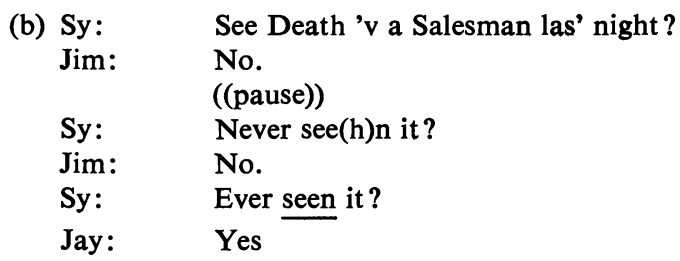

[Adato: 2:9]

Here Jim and Jay are selected as next speakers by Sy, and Sy's turns are allocated by selfselection. Concerning Sy's selections of next speaker, note that whether or not the first interchange involves a glance-selected recipient, the second and third are at least partially lexically accomplished, in the uses of 'never' and 'ever'.

The above should not be taken as evidence that questions are always self-selected, or that answerer turns are the product of 'current selects next' techniques, as may be seen in the following:

(c) Jim: Any a' you guys read that story about Walter Mitty?

Ken: I did,

Roger: $\quad \overline{M m}$ hmm

[GTS: $5: 25]$

All the turns here are allocated by self-selection. For further discussion and additional data on turn-allocation, see $\$ 4.12$ below. 
3.3. RULEs. The following seems to be a basic set of rules governing turn construction, providing for the allocation of a next turn to one party, and coordinating transfer so as to minimize gap and overlap.

(1) For any turn, at the initial transition-relevance place of an initial turnconstructional unit:

(a) If the turn-so-far is so constructed as to involve the use of a "current speaker selects next' technique, then the party so selected has the right and is obliged to take next turn to speak; no others have such rights or obligations, and transfer occurs at that place.

(b) If the turn-so-far is so constructed as not to involve the use of a 'current speaker selects next' technique, then self-selection for next speakership may, but need not, be instituted; first starter acquires rights to a turn, and transfer occurs at that place.

(c) If the turn-so-far is so constructed as not to involve the use of a 'current speaker selects next' technique, then current speaker may, but need not continue, unless another self-selects. ${ }^{14}$

(2) If, at the initial transition-relevance place of an initial turn-constructional unit, neither 1a nor $1 \mathrm{~b}$ has operated, and, following the provision of $1 \mathrm{c}$, current speaker has continued, then the rule-set a-c re-applies at the next transitionrelevance place, and recursively at each next transition-relevance place, until transfer is effected.

3.4. THE ORDERING OF THE RULES serves to constrain each of the options which they provide. The fact that $1 \mathrm{a}$ is the first rule to apply does not mean that its option is free of constraints imposed on it by the presence, in the set, of rules which

${ }^{14}$ Examples are:

(a) Ava:

$\mathrm{He}$, he 'n Jo were like on the outs, yih know?

$\rightarrow$ Ava:

[So uh,

$\rightarrow$ Bee: $\quad$ They always are(hh)hhh

[TG:JFr:20]

(b) Claire: So then we were worse o- 'n she an' she went down four,

$\rightarrow$ Claire: But uhm

(1.5)

$\rightarrow$ Claire $\quad[\mathrm{Uh}$

$\rightarrow$ Chloe: Well then it was her fault [Claire,

Claire: $\quad$ Yeah she said one no trump, and I said two, an' then she went back t' two ...

[Ladies: 2:2:3:14]

(c) Roger: That's a joke that police force. They gotta hunderd cops around the guy en so(h)me guy walks in and says I'm gonna shoot you and shoots him.

$\rightarrow$ Roger: :hhmhhh heh

$\rightarrow$ Roger: En it's the president's assassin y' know,

(0.9)

$\rightarrow$ Roger: They're wonder[ful.

$\rightarrow$ Louise: $\quad-$ Hm- Now they're not even sure.

[GTS:1:2:86] 
woulD apply if $1 \mathrm{a}$ did not. Thus the option of rule $1 \mathrm{~b}$ applies if rule $1 \mathrm{a}$ 's option has not been employed; hence, for rule 1a's option to be methodically assured of use, it needs to be employed before the initial transition-relevance place of an initial unit. The operation of rule la's option thereby is constrained by rule $1 \mathrm{~b}$ 's presence in the set, independent of whether rule 1b's option is actually employed. Similarly, for rule 1b's option to be methodically assured of application, given the presence in the set of rule 1c, it will need to be employed at the initial transition-relevance place of an initial unit, and before current speaker's option to continue (rule 1c) is invoked. If $1 \mathrm{c}$ is thus invoked, then rule 2 will apply; the rule set a-c will re-apply; and rule 1a's option will again take priority over that of rule $1 \mathrm{~b}$. Thus the operation of rule $1 \mathrm{~b}$ is constrained by rule 1c's presence in the set, regardless of whether it is actually employed. Having noted that lower-priority rules thus constrain the use of higher-priority options, we should recall that the constraints imposed on lowerpriority rules by higher-priority ones are incorporated in the rule-set itself.

The rules provide an ordering of the application of the technique groups (i.e. the two groups of turn-allocational techniques) that makes the inclusion of the two types of techniques in the rule-set compatible with 'one speaker at a time', obviating a violative potential of their joint inclusion were they not ordered. If the technique groups were not ordered-e.g., if both were usable on any occasion on which one was usable - then the very techniques whose operation should yield only one next speaker would permit more than one party to be selected. That possibility would be provided because each type of technique involves use by a different party; and unless the party performing self-selection were the same party being selected by current speaker, more than one next speaker will have been selected. The rule-set's ordering of the application of the techniques removes this possibility. Furthermore, the 'first starter has rights' provision of rule $1 \mathrm{~b}$ provides an ordering, within the possibilities provided by that technique group, which is addressed to the possibility of multiple self-selection opened up by that technique.

Minimization of gap and overlap is accomplished in two ways: one localizes the problem, the other addresses it in its localized forms. The rule-set, along with the constraints imposed mutually by the options in it, eliminates gap and overlap from most of conversation by eliminating gap and overlap from most single turns. The rules provide for turn-transfers occurring at transition-relevance places, wherever the use of the allocational technique has been constructionally accomplished. Thus 'current speaker selects next' techniques may be accomplished at the very beginning of the unit-type employed in a turn (e.g. by the use of an address term for certain unit-types); but the accomplishment of turn-transfer does not occur until the first possible transition-relevance place. The use of self-selection techniques is contingent on the non-use of 'current selects next' techniques, and those may be applied at any point up to the first transition-relevance place, hence self-selection may not be exercised (the technique selected or the transfer attempted) until the first transition-relevance place. Current speaker may continue (rule 1c) if selfselection is not done, thus recycling the rules: hence self-selection, to be assured, must be done AT the transition-relevance place. ${ }^{15}$ The turn-taking rule-set thus

\footnotetext{
${ }^{15}$ We speak of 'transition-relevance PLACE' in order to avoid choosing, with a term, between alternative and possibly compatible features of transition coördination which we are currently
} 
provides for the localization of gap and overlap possibilities at transition-relevance places and their immediate environment, so that the rest of a turn's 'space' is cleansed of systematic bases for their possibility.

4. HOW THE SYSTEM ACCOUNTS FOR THE FACTS. In this section, we bring the system just described to bear on the initially noted, grossly apparent facts, to see how the model either produces them or is compatible with them. In addition, a variety of other, not so readily apparent, findings that attend the model will be examined. Sections here correspond to the numbered observations in $\S 1$ above.

4.1. Speaker-change recurs, or at least occurs. This turn-taking system provides a systematic basis for speaker-change and its recurrence, while not making them automatic. The possibility of speaker-change is built in, recurrently within any single turn's construction, and recurrently for each new turn, because, any unittype instance out of which a turn may be constructed will reach a transition-relevance place, at which the first two priority options involve transfer of turn to a next speaker. Speaker-change and its recurrence are not automatic because, at each transition-relevance place, the options provided by rules $1 \mathrm{a}$ and $1 \mathrm{~b}$ may not be exercised, while the option provided by rule $1 \mathrm{c}$ is. For as long as this combination is applied at each transition-relevance place encountered, there will be a sequence in which there is no speaker-change. Speaker-change occurrence is a special case of speaker-change recurrence, by a restriction too complicated to deal with here. ${ }^{16}$

4.2. Overwhelmingly, one party talks at a time. This fact is provided for by two features of the system: First, the system allocates single turns to single speakers; any speaker gets, with the turn, exclusive rights to talk to the first possible completion of an initial instance of a unit-type-rights which are renewable for single next instances of a unit-type under the operation of rule 1c. Second, all turntransfer is coördinated around transition-relevance places, which are themselves determined by possible completion points for instances of the unit-types.

4.3. Occurrences of more than one speaker at a time are common, but brief. We have already discussed how the rule-set localizes occurrences of overlap. We turn here to the systematic bases for their occurrence and for their briefness.

There are a number of systematic bases for the occurrence of overlap, of which we can mention only a few:

(a) Rule $1 \mathrm{~b}$, in allocating a turn to that self-selector who starts first, encourages earliest possible start for each self-selector. It thereby provides for overlap by competing self-selectors for a next turn, when each projects his start to be earliest

investigating. There are aspects of transition coördination which seem to require the notion of a 'space' for transitions, e.g. inter-turn silences which are not treated by participants as gaps or pauses. And there are aspects of transitions for which the notion of a transition 'point' seems correct; e.g., the end of a question which selects a next speaker seems often to constitute a transition point-a new turn starts there whether or not talk by another is immediately begun. 'Space' and 'point' need not be mutually incompatible, as later discussion will indicate. The concerns of this paper seem to us not to turn on this order of detail, and we avoid prejudicing the issue by the use of 'place', of which both 'space' and 'point' are possible specifications.

${ }^{16}$ Speaker-change occurrence is the case of a two-turn sequence, e.g. just 'A: Hello; B: Hello', with nothing following. 
possible start at some possible transition-relevance place, producing simultaneous starts. Examples:

(1) Parky:

Oo what they call them dogs that pull the sleighs.

Parky: S- sledge dogs.

(0.7)

Old Man: Oh uh[:: uh

$\rightarrow$ Tourist: $\quad$ UUh- Huskies. $=$

$\rightarrow$ Old Man: $=$ [Huskies. Mm,

$\rightarrow$ Parky: $\quad=$ Huskies. Yeh Huskies.

(2) Lil: $\quad$ Bertha's lost, on our scale, about fourteen pounds.

Damora: Oh [:: no:: .

$\rightarrow$ Jean: $\quad$ Twelve pounds I think wasn't it. =

$\rightarrow$ Daisy: $\quad=$ Can you believe it?

$\rightarrow$ Lil: $\quad=$ Twelve pounds on the Weight Watcher's scale.

$\begin{aligned} \text { (3) } & \rightarrow \text { Mike: } & & \text { I know who d' guy is. }= \\ & \rightarrow \text { Vic: } & & =\left[\begin{array}{l}\text { He's ba:: d. } \\ \text { You know the gu:y? }\end{array}\right.\end{aligned}$

[Labov et al.: Travel Agency:2]

[Frankel:67]

It is notable that such simultaneous starts testify to the independent-for-each-party projectability of possible completion points of the talk that occupies current turn.

(b) Another basis of overlap derives from the projectability of possible completion or transition-relevance places. Variation in the articulation of the projected last part of a projectably last component of a turn's talk, which is in fact a consequential locus of articulatory variation, will expectably produce overlap between a current turn and a next:

(4) A:

B:

(5) B:

A:

(6) A:

B:

(7) A:

B:

(8) A:

B:
Well if you knew my argument why did you bother to a: [sk.

Because I'd like to defend my argument.

[Crandall:2-15-68:93] Well it wasn't me $\left[\begin{array}{l}: \\ \text { No, but you know who it was. }\end{array}\right.$

[Civil Defense HQ:2:88]

Sixty two feet is pretty good si:[ze.

Lh:: boy.

[NB:I:6:7]

Terr::ifi::[c.

I think it's much better than about a:: black 'n white nuns going down stai:rs.

So yer not a Pontiac People anymo(hh) [re.

[GTS:1:2:24]

a bi:::11,

[GTS: $1: 2: 28]$

The addition of optional elements which can specifically go after first possible completion, without intending continuation (e.g. terms of address and etiquette), will be productive of similarly structured overlaps (and their absence, for that matter, can be productive of similarly structured gaps). ${ }^{17}$ Examples:

(9) A:

Uh you been down here before havenche.

Yeh.

[NB:III:3:5]

${ }^{17}$ Cf. Jefferson 1973, which deals specifically with this matter. 


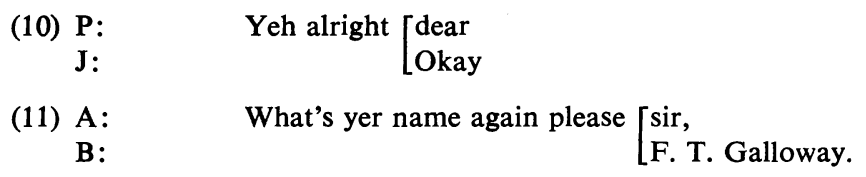

[Trio:II: 12]

[F. T. Galloway. [FD:IV:35]

As for the briefness of occurrences of more than one speaker at a time, one obvious reason is that they appear at transition-relevance places, i.e. places where current speakers can or should exit, thus removing a component of the overlap, and thereby the overlap.

4.4. Transitions (from one turn to a next) with no gap and no overlap are common. Together with transitions characterized by slight gap or slight overlap, they make up the vast majority of transitions. The components and the rule-set, in organizing transfer exclusively around transition-relevance places, provide for the possibility of transitions with no gap and no overlap. We have already described some structural bases for the occurrence of some gap and some overlap-bases which also provide for such gap or overlap being slight, and bases which are consequences of the very rule-set which otherwise secures transitions with no gap and no overlap. ${ }^{18}$

4.5. Turn order is not fixed, but varies. This fact is produced by a combination of two features in the system: (a) single turns are allocated at a time; and (b) for each such allocation, a series of options is provided, each of which can provide for different next speakers. Thus ordering of speakers, being locally controlled (i.e. turn by turn), can vary.

We can add that, while turn order varies, it does not vary randomly. One bias that is particularly important is for speaker just prior to current speaker to be selected as next speaker:

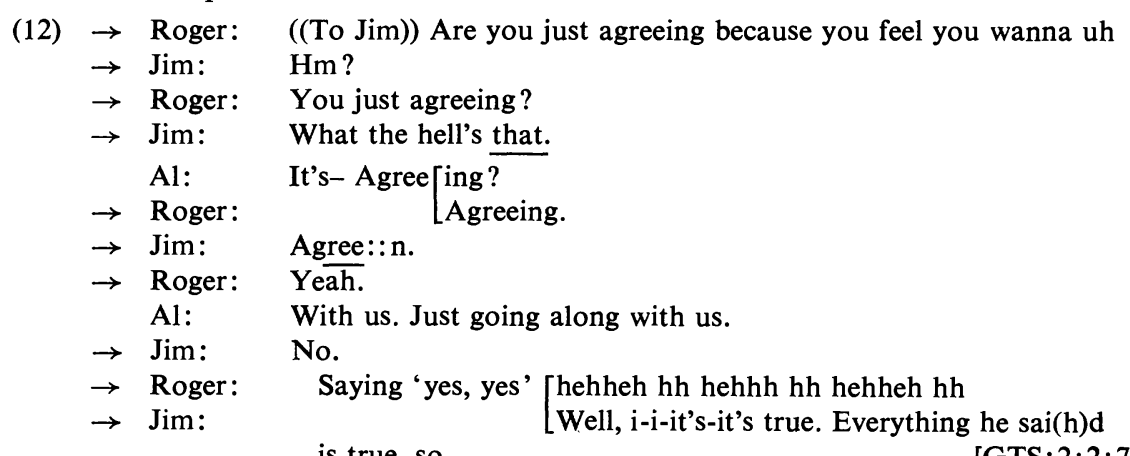

$$
\text { is true, so }
$$

[GTS:2:2:70]

The patterns 'Roger as last and next for Jim' and 'Jim as last and next for Roger' work across this whole sequence; Al's first entry does not come off as the effective turn, and his second is initially shaped as an addition to another's turn. See also ex. (b) in fn. 13, above, and ex. 14 below.

\footnotetext{
${ }^{18}$ The relationship between the brief gap that may characterize an accomplished transition and such extended silences as do occur within conversations, characteristically between sequences, will not be considered here, except to note that rule $1 \mathrm{~b}$ does provide that selfselection is optional, while rule 1c provides that 'same speaker continuing' is also optional. This combination allows the possibility of a lapse, which will be considered in $\$ 4.11$ below.
} 
The sources of this bias are external to the turn-taking system's basic organization, and cannot be detailed here (cf. $\$ 4.12$ below, point b). What is to be noted here is that the rule-set allows such a bias to operate, via the ordering of the options which make up the rule-set. It is the priority of the 'current speaker selects next' option which allows the bias to occur.

One importance of the bias is this. Because of it, the possibility of 'colloquy' is systematically provided; this involves, in the first instance, the possibility of local monitoring for hearing, understanding, agreement etc. It is, indeed, directly after any turn that problems dealing with hearing, understanding etc. that turn are preferably raised; the means of raising them involves the selection of the last speaker to be next, to repeat, clarify etc. ${ }^{19}$

4.6. Turn size is not fixed, but varies. The variability of turn size has its grossest sources in two features of the system we have described:

(a) The availability of a range of unit-types out of which turns may initially be constructed (a range that varies on the parameter of length), and the availability to a current speaker of free selection among them, provide that for a set of turns, each of which will have contained only the single unit to which a speaker is initially entitled by virtue of having a turn, the turns in the set may have varying turn sizes. ${ }^{20}$ In this regard, sentential constructions are the most interesting of the unittypes, because of the internally generated expansions of length they allow-and, in particular, allow BEFORE first possible completion places: ${ }^{21}$

(13) Ken:

I still say though that-if you take if you take uh a big fancy car out on the road and you're hotroddin' around, you're- you're bound to getyou're bound to get caught, and you're bound to get shafted.

[GTS:2]

Thus sentential constructions alone do provide for turn-size variability. It is in terms of this expandability of sentential construction, before first possible completion, that the 'projectable completion' feature of component 1 in the turn-taking system is to be understood. Sentential constructions are capable of being analysed in the course of their production by a party/hearer able to use such analyses to project their possible directions and completion loci. In the course of its construction, any sentential unit will rapidly (in conversation) reveal projectable directions and conclusions, which its further course can modify, but will further define (cf. Schegloff, Ms).

(b) A second source for turn-size variation is this. Rule 1c provides for the possibility that any current speaker may get a chance to produce more than a single instance of a unit-type (cf. ex. (c) in fn. 14). The possibility of rule 1c's operation means that the system does not define maximum turn size, while the turn-constructional component does determine minimal turn size. Since rule 1a provides any current speaker with a turn-termination technique usable at any transitionrelevance place, the variability of turn size is systematically provided for, independent of source (a).

${ }^{19}$ As in exx. a-g in fn. 12, a-c in fn. 13, a-c in fn. 14, 1-3, 12, and 21-23 below.

${ }^{20}$ Varying sizes of single-unit turns are illustrated in exx. a-g in fn. 12, a-c in fn. 13, and elsewhere.

${ }^{21}$ For short single-sentence turns, see ex. $b$ in fn. 12, and ex. (c) in fn. 13 above. 
4.7. Length of conversation is not specified in advance. The turn-taking system itself says nothing directly about the length or closing of conversation. It does, however, put constraints on how any system of rules for achieving conversational closing (and thus length) could operate. E.g., by virtue of rule 1a, ending should not occur, and rarely does, after a turn in which a 'current speaker selects next' technique has been used.

Length or closing of conversation is governed by other kinds of organization than the turn-taking system. One such organization has already been described by Schegloff \& Sacks 1973; we note here only that the close of conversation, and therefore its length, is generated in a manner internal to its developing course (just like turn-length, as earlier described). Not all conversational activity for which the turn-taking system is relevant occurs in instances of the unit 'a single conversation' for which that closing structure is relevant. The turn-taking system is, in the first instance, a system for 'sequences of talk'. There is an order of organization for 'types of sequences', by reference to which length of conversation for units of that sort may be determined. The turn-taking system itself is compatible with varying lengths, and does not predetermine any length.

4.8. What parties say is not specified in advance. We may compare ceremonies, where what is said by the participants may be specified in advance to any degree desired. In debates, the order in which the participants talk is directly related to the character of what they are to say, the parties being characterizable as 'pro' and 'con', and the turns in which they talk as, e.g., 'rebuttal' and 'counterrebuttal'. The turns which an 'interview system' organizes alternatingly are 'questions' and 'answers'. In these and other speech-exchange systems, the turntaking organization employs, as part of its resources, the grosser or finer prespecification of what shall be done in the turns it organizes.

By contrast with these other speech-exchange systems, the turn-taking organization for conversation makes no provision for the content of any turn, nor does it constrain what is (to be) done in any turn. Neither the components nor the rule-set includes features bearing on this matter. But this is not to say that there are no constraints on what may be done in any turn. 'First turns' in a structurally characterizable set of circumstances properly take 'greetings'; and 'next turns' can, in a variety of closely describable ways, be constrained by 'prior turns'. We note only that in conversation, such constraints are organized by systems external to the turn-taking system. One aspect of conversation's flexibility is a direct and important consequence of this feature of its turn-taking organization: its turntaking organization (and thus conversational activity per se) operates independently of various characterizations of what occupies its turns, the 'topic(s)' in them.

As with other points that we have made about variance, the non-fixedness of what parties say should be modified by noting a bias operative in it. The group of allocation techniques which we have called 'current speaker selects next' cannot be used in just any utterance or utterance-type whatever. Rather, there is a set of utterance-types, adjacency pair first parts, ${ }^{22}$ that can be used to accomplish such a selection; and with the constraint to employ one of those, there are constraints on

${ }^{22}$ See $\$ 4.12$ below—and, for further elaboration, Schegloff \& Sacks. 
what a party can say. But note: (a) no party is constrained in any turn to use a 'current speaker selects next' technique; and (b) any party interested in doing so has a considerable-sized set of utterance-types to choose from, each of which may accomplish the selection. And while a party selected by the use of such a technique will be constrained in what he says in the turn so allocated (e.g., being under some constraints to 'answer' if the technique employed to select him was 'question'), these constraints are given by the organization of the 'types of sequences' whose first parts serve as the 'current speaker selects next' techniques, ${ }^{23}$ and not by the turn-taking system per se. That the conversational turn-taking system does not constrain what occupies its turns frees the turns for use by other systems, and those systems' components are then subject to the organizational contingencies of the turns that they occupy.

4.9. Relative distribution of turns is not specified in advance. The rule-set maximizes the set 'potential next speakers': i.e., rule 1a allows current speaker to select any other party as next speaker; rule $1 \mathrm{~b}$ allows any party other than current speaker to self-select as next speaker. The combination provides alternative routes whereby any current non-speaker is potential next speaker. Furthermore, rule 1c has the consequence of not excluding even current speaker from next speakershipexcept that the system permits the use of that option to be treated as a within-turn event, counting not as an instance of a turn-allocation to a same speaker, but as an increment to turn size. The rule-set operates at each transition-relevance place, and at each such place any party to the conversation can speak next; hence the rule-set provides for the possibility of any over-all distribution of turns, and frees turndistribution for manipulation by such interests as can be realized with the distribution of turns. ${ }^{24}$

${ }^{23}$ Discussions of a number of types of sequences have been published or are in press: e.g., summons-answer sequences (Schegloff 1968), side sequences (Jefferson 1972), insertion sequences (Schegloff 1972), closing sequences (Schegloff \& Sacks 1973), story sequences (Sacks 1974), expanded sequences (Jefferson \& Schenkein, MS), and various others (e.g. Jefferson 1973).

${ }^{24}$ E.g., it is sometimes suggested in the literature on small groups that relative distribution of turns (or some similar measure) is an index of (or medium for) power, status, influence etc. Thus Bales (1970:62, 76-7):

It is true that the amount of speaking is not a completely reliable cue to status-the overt behavior of certain persons or subgroups sometimes seems markedly out of conformity with what one would expect if amounts of participation followed the conventional status order. Nevertheless, paying attention to who speaks how much and to whom can be unexpectedly enlightening ...

Who speaks how much to whom in the group is a 'brute fact' characterizing the actual present situation. Speaking takes up time. When one member speaks, it takes time and attention from all other members of the group, some of whom may want to speak themselves. To take up time speaking in a small group is to exercise power over the other members for at least the duration of the time taken, regardless of the content. It is an exercise of power that may not coincide at all with the status position of the individual based on outside criteria, or even on special criteria developed within the group ...

Within the small group the time taken by a given member in a given session is practically a direct index of the amount of power he has attempted to exercise in that period.

We suggest, in the next paragraph, another kind of caution, in addition to those undoubtedly observed by researchers in this area, which might be taken in such uses of relative turndistribution by professional analysts. 
Since relative distribution of turns is the cumulative outcome, at any current point in a conversation, of the turn-by-turn determinations of turn-order, the biases operative in turn-order determination (one of which was noted in $\$ 4.5$ above) may result in skewings intrinsic to the turn-taking system, in the over-all distribution of turns to any point.

4.10. Number of parties can vary. The turn-taking system provides for this in a manner similar to that by which it provides for conversation of varying lengths. As it is built to organize but two turns at a time, current and next, and the transition from the one to the other, without restriction on the number of such currents and nexts it can serially organize, so also it organizes but two speakers at a time, current and next, and is not overtly directed to the size of the pool from which they are selected. In not providing for number of speakers beyond current and next, the system is compatible with different numbers of participants from conversation to conversation. Further, in being compatible with differing numbers of participants, it is compatible with varying numbers of participants within any single conversation, since there are mechanisms for entry of new participants and exit for current participants (though we will not describe them here).

Though the turn-taking system does not restrict the number of parties to a conversation it organizes, still the system favors, by virtue of its design, smaller numbers of participants. This is related, most centrally, to the bias operative on mechanisms of turn ordering, discussed in $\S 4.5$ above. Most simply put: the rule-set refers to only two speakers, current and next; and the turn-order bias, when it operates, selects 'just prior to current' to be next. In two-party conversation, the two speakers to whom the rule-set refers, and for whom the turn-order bias works, comprise all the parties to the conversation, and it is not in point to speak of a turnorder 'bias'. The 'last as next' bias, however, remains invariant over increases in the number of parties - and, with each additional increment in number of parties, tends progressively to concentrate the distribution of turns among a sub-set of the potential next speakers. With three parties, one might be 'left out' were the bias to operate stringently; with four parties, two would be 'left out', etc.

It can be noted that some of the variabilities we have been discussing are connected (e.g. number of parties and turn order) and have a range of differential relevancies; the partial ordering of these may be illustrated by reference to the 'number of parties' parameter. Thus, for two parties, the relevant variability is not differential distribution of turns (given that they will have alternating turns), but differential turn size. With three parties, differential distribution of turns becomes relevant. While turn size remains relevant, a bias toward smaller turn size is introduced. With the introduction of a third party, 'next turn' is no longer guaranteed to (or obliged for) any current non-speaker. In two-party conversation, a current non-speaker can pass any given transition-relevance place which is nonobligatory (i.e., where 'current selects next' technique has not been used) with full assurance of being 'next speaker' at some point; but with three or more parties, this is not assured. If a current non-speaker, interested in speaking next, should not self-select at a next transition-relevance place, then some other current non-speaker might self-select, and in his turn select someone else; or current speaker might 
continue, and in his continuation select some other current non-speaker. Therefore a current non-speaker, if interested in speaking next, will be under constraint to self-select at first possible transition point, and at each successive such point. Furthermore, if a current speaker is interested in choosing among potential next speakers, he will be under constraint to accomplish the selection before first possible transition place (at which transition-relevance place transfer then occurs, via rule 1a), lest an undesired current non-speaker self-select at that point. From both directions, then, there will be pressure for minimization of turn size, distinctively operative with three or more parties.

With four parties, a type of variability we have not so far considered is introduced, i.e. variability in the number of turn-taking systems in operation. There are mechanisms for the schism of one conversation into more than one conversation. These mechanisms can operate when at least four parties are present, since then there are enough parties for two conversations. With four parties, then, schism is a systematic possibility. We earlier noted that the turn order bias of 'last speaker being next speaker' becomes a relative distributional bias with three or more parties. With four or more parties, a possible check on it is introduced by the possibility of schism. If there is an interest in retaining, in a single conversation, some current complement of parties (where there are at least four), then the turntaking system's means for realizing that effort involve 'spreading turns around', since any pair of parties not getting or taking a turn over some sequence of turns can find their mutual accessibility for getting into a second conversation:

(14) Ethel, Ben, and Max are visiting Bill and Lori. They've brought a lot of food, including a salami Max took out of his refrigerator. Ben is wearing his new combination eyeglasses/hearing-aid. At this point, Lori is offering drinks. [Schenkein:II:13drastically simplified version]

Ethel: I'll take scotch, if you have it,

$\rightarrow$ Ben: You're gonna have to quit yelling, you see,

Ethel: $\quad$ Oh lookit his ear!

$\rightarrow$ Lori: $\quad$ Oh that's right. You got- I know I noticed when he came in.

$\rightarrow$ Ben: $\quad$ Did you notice it?

$\rightarrow$ Lori: $\quad$ Yeah how do you like it.

$\rightarrow$ Ben: It's fantastic.

Ethel: Except the thing presses into his head.

$\rightarrow$ Ben: $\quad$ It- it hurts me terrible I have to go down and get it adjusted.

$\rightarrow$ Lori: Yeah.

$\rightarrow$ Ben: It kills me right here.

$\rightarrow$ Lori: It's,

$\rightarrow$ Ben: The glasses are tight I feel it.

Max: Is the salami dry? puts it on,

Ben: Nothin,

Lori: Will I hear it?

Lori: Will I hear it?

Ben: You gotta put this inside the ear. $\begin{array}{ll}\text { Bill: } & \text { Bill: little bit, } \\ \text { But it's good that way. }\end{array}$

Lori: And then will it be real loud? Bill: (Because) all the fat evaporates. 
Ben: Well, yeah. Probably will be because you're-

Lori: It won't be too loud,

Ethel: Y'know we had-

Ben: Well I could adjust the volume, I have it-

Ethel: We knew somebody who used to hang-

Ethel: Hang it-

Ben: I have it down almost all the way.

Lori: Okay

Ethel: Leave it outside all the time

Ben:

Yeah.

Ethel:

So it would $\overline{\text { dry }}$ out hearing in this ear.

In that regard, an interest in retaining the full complement of parties encourages a distribution of turns different from the distributional product of the turn-order bias.

It should be noted that the possibility of schism introduced by a fourth party can serve as a check on turn-distribution introduced by a third party, just as the turn-distribution introduced by a third party serves as a check on turn-size mechanisms operative for two parties. But it should also be noted that this schism as a 'check' on turn-distribution is equivocal-since turn-distribution can, by the same measure, be used as a means by some parties for encouraging schism by others.

4.11. Talk can be continuous or discontinuous. It is continuous when, for a sequence of transition-relevance places, it continues (by another speaker, or by the same continuing) across a transition-relevance place, with a minimization of gap and overlap. Discontinuities occur when, at some transition-relevance place, ${ }^{25}$ a current speaker has stopped, no speaker starts (or continues), and the ensuing space of non-talk constitutes itself as more than a gap-not a gap, but a lapse:

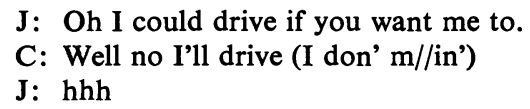

J: I meant to offah.

$\rightarrow \quad(\overline{16} .0)$

J: Those shoes look nice when you keep on putting stuff on 'em.

C: Yeah I 'ave to get another can cuz cuz it ran out. I mean it's a//lmost(h) ou(h)*t $=$

J: Oh:::ah*he 'hh heh=

C: = yeah well it cleans 'em and keeps // 'em clean.

J: Yeah right $=$

C: = I should get a brush too and you should getta brush 'n // you should-* fix your hiking boo//ts

$\mathrm{J}$ : Yeah suh::

J: my hiking boots

C: which you were gonna do this weekend.

J: Pooh, did I have time this wk- well::

C: Ahh c'mon =

$\mathrm{J}$ : = wh'n we get- (uh::kay), I haven't even sat down to do any-y' know like 'hh today I'm gonna sit down 'n read while you're doing yur coat, $(0.7)$ do yur- hood.

${ }^{25}$ What follows is not true for just any transition-relevance place, but only for certain classes of transition-places, characterizable by reference to the organization of sequences, not the organization of turn-taking. 


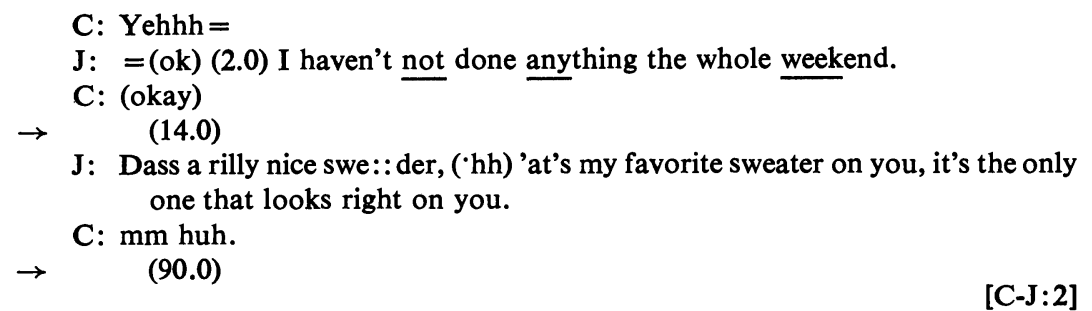

That talk can be continuous is provided in the rules by the fact that each option provides a procedure whereby some next speaker can be located at any transitionrelevance place. The exercise of options to talk, in the ordered fashion in which they become available at each transition-relevance place, yields a sequence of continuous talk. But since each rule provides an option (and the last of the ordered set of rules in particular provides an option, rather than, e.g., a backstop, providing a speaker if no other option has provided one), the possibility of discontinuity also exists. At any transition-place where none of the options to speak has been employed, the possibility of a lapse, and thus discontinuous talk, arises.

A variety of constraints may operate on the possible placement of lapses. An important one is given by the turn-taking system itself. If rule $1 \mathrm{a}$ is employed in a turn's talk, in selecting a next speaker to follow its possible completion, no lapse can properly occur; i.e., a silence after a turn in which a next has been selected will be heard not as a lapse's possible beginning, nor as a gap, but as a pause before the selected next speaker's turn-beginning. We are saying: among the means used for reducing gap are classificatory decisions which seem themselves orderly as to the alternative applicability of 'gap', 'pause', and 'lapse' as ways of conceiving the appearance of silence in a conversation. ${ }^{26}$

If rule 1a has been employed in a current turn's talk, then the possibility of a lapse immediately following it is ruled out. A lapse occurs when rule la has not been employed, by a recycling of the options provided by rules $1 \mathrm{~b}$ and $1 \mathrm{c}$. That is, when rule 1a has not been employed, next turn is available to a self-selecting next speaker; should no one self-select, then current speaker may self-select to continue (in his continuation possibly applying rule 1a). Should current speaker not selfselect to continue, rule 1a remains inoperative and there is further space (another round) available for self-selection - and, in the absence of self-selection by another, self-selection by current speaker to continue, etc. That is, a series of rounds of possible self-selection by others and self-selection by current to continue-rules $1 \mathrm{~b}$ and $1 \mathrm{c}$ - may develop, in none of which are options to talk exercised, with the thereby constituted development of a lapse in the conversation. ${ }^{27}$

${ }^{26}$ I.e., parties' treatment of silence in conversation is contingent on its placement. To put it roughly: intra-turn silence (not at a transition-relevance place) is a 'pause', and initially not to be talked in by others; silence after a possible completion point is, initially, a gap, and to be minimized; extended silences at transition-relevance places may become lapses. But some silences are transformable. Thus, if a developing silence occurs at a transition-place, and is thus a (potential) gap, it may be ended by talk of the same party who was talking before it; so the 'gap' is transformed into a 'pause' (being now intra-turn). This is one way that 'gap' is minimized (cf. exx. (b) and (c) in fn. 14 above, and ex. 1.)

${ }^{27}$ The option-cycle relationship between rules $1 \mathrm{~b}$ and $1 \mathrm{c}$, as presented here, may help to explain results like those reported by Matarazzo \& Wiens, to the effect that 'reaction time 
4.12. Turn-allocation techniques are used..$^{28}$ An initial observation that nextspeaker selection techniques operate in conversation can be made from 'obvious cases', such as the fact that an addressed question selects its addressee to speak next-or that, in starting to speak when not selected, a party selects himself to speak. ${ }^{29}$ Two consequences are suggested: (1) since obvious cases suggest that selection techniques are operating, there is reason for searching out techniques which are less obvious, but expectably used; (2) the obvious cases suggest that the techniques may be grouped, and suggest a kind of grouping, which can organize the search for other techniques.

There are indeed other allocation techniques; and they do appear to be grouped as 'current selects next' and 'self-selection'. The most we can do here is briefly describe several techniques, indicating that they naturally fall into such groups.

(a) The 'obvious' case of an addressed question is but a special case of a class of utterance types, or 'type of sequence' parts, which share the property of possibly selecting next speaker. That is, 'question' is one instance of the first part of a sequential unit elsewhere termed 'adjacency pairs' (cf. Schegloff \& Sacks). That class of units also includes such sequences as 'greeting-greeting,' 'invitationacceptance/decline' etc.:

(16) Complaint/denial

Ken: Hey yuh took my chair by the way an' I don't think that was very nice.

Al: I didn' take yer chair, it's my chair.

[GTS:1]

(17) Compliment/rejection

A: I'm glad I have you for a friend.

B: That's because you don't have any others.

[FN]

(18) Challenge/rejection

A: It's not break time yet.

B: I finished my box, so shut up.

(19) Request/grant

'7:19. Raymond sat back in his chair. He was nearly finished with his breakfast. He said in a slightly complaining tone, "Mommie, I don't want this other piece of toast." His mother said casually, "You don't? Well, O.K., I guess you don't have to eat it." He finished eating his breakfast.'

[Barker \& Wright 1951:22]

For offer/accept and offer/reject, cf. ex. (a) in fn. 13; for question/answer, cf. ex. (b), ibid.; for offer/reject and two compliment/accepts, cf. ex. 15; for instruct/receipt, cf. Goldberg, Ms; for still others, cf. the papers cited in fn. 23.

latencies' (the time intervening between one speaker's completion and a next speaker's start in two-party conversation) are shorter, on the average, than are 'initiative time latencies' (the time intervening between one speaker's 'completion' and the start of a 'follow-up' utterance by same speaker), the other participant not having talked. It was, in part, the encountering of similar data in our materials that prompted that formulation of the rules.

${ }^{28}$ Since turn-allocation has appeared both as an empirical fact about conversation and as part of the components and rule-set, the discussion of it is more extensive than that in other sections, and is concerned to explicate, at least partly, that part of the rule-set.

The theme of showing the compatibility of the model with the gross facts is different in the case of turn-allocation than in that of other facts, for it is a central design outcome of the model to make multiple allocation techniques compatible with one-speaker-at-a-time by its ordering of them (see $\$ 3$ above).

${ }^{29} \mathrm{See}$ fn. 13 above, and ex. 21 below. 
Some features of this class of units have been described elsewhere, and others will be described in later reports. Their first components can be termed 'first pair-parts'; they set constraints on what should be done in a next turn (e.g., a 'question' making 'answer' specially relevant for next turn), but do not by themselves allocate next turn to some candidate next speaker. They are, nonetheless, the basic component for selecting next speaker, since it is primarily by affiliation to a first pair-part that the apparently most effective device for selecting next speakeraddressing someone-in fact works. ${ }^{30}$ Thus an important general technique whereby current speaker selects next-perhaps the central one-involves the affiliation of an address term (or some other device for achieving 'addressing', e.g. gaze direction) to a first pair-part. ${ }^{31}$ But addressing a party will not necessarily, in itself, select him as next speaker. Thus A, addressing a question to B, selects him as next speaker; but when B speaks next and addresses an answer to A (a second pair-part), $\mathrm{A}$ is not necessarily selected as next speaker:

Sharon: You didn' come tuh talk tuh Karen?

Mark: No, Karen- Karen 'n I 're having a fight, (0.4) after she went out with Keith an' not with (me).

$\rightarrow$ Ruthie: hah hah hah hah

$\rightarrow$ Karen: Wul Mark, you never asked me out.

$\begin{array}{lll}\text { S: } & \text { Oscar did you work for somebody before you worked for Zappa? } \\ \text { O: } & \text { Yeh, many many. (3.0) Canned Heat for a year. } \\ \text { S: } & \text { Didya? } \\ \text { O: } & \text { Poco for a year. } \\ \rightarrow \text { T: } & \text { ooh when they were good? } \\ \text { O: } & \text { Bangor Flunt Madura fer a y- couple years } \\ \text { T: } & \text { Bangor Flunt Madura? } \\ \text { O: } & \text { Bangor Flying Circus. } \\ \rightarrow \text { J: } & \text { Oh: yeh I // remember Bangor Flying Circus }\end{array}$

[Toni-6:372-380]

Cf. the data cited in fn. 31 . In each case, note that the speaker after an answer is not the questioner, to whom the answer was addressed, although in ex. 21 there are also sequences in which the questioner talks next after the answer.

(b) One variant of the use of first pair-part to select a next speaker will accomplish a next-speaker selection without addressing or any such technique, but will select only a particular other as next speaker. This device is a variant of the 'question', a type of first pair-part-namely repetitions of parts of a prior utterance with 'question' intonation (cf. Jefferson 1972); a variety of 'one-word questions' such as what?, who? etc.; and other 'repair techniques':

$$
\begin{aligned}
& \text { Ben: They gotta- a garage sale. } \\
& \rightarrow \text { Lori: Where. } \\
& \text { Ben: On Third Avenue. }
\end{aligned}
$$

[Schenkein:II:38]

Cf. exx. a-f in fn. 12, 12 ('Jim: Agree::n'), and 21 ('T: Bangor Flunt Madura?')

This question-type may be used without any affiliated technique for selecting a particular other, and thereby selects the just prior speaker as next speaker. These repair techniques constitute a central device that introduces the turn-order bias (and, cumulatively, the turn-distribution bias) noted earlier: the only systematic

30 'Addressing' itself can be done as a first pair-part, e.g. as in summoning; cf. Schegloff 1968. ${ }^{31}$ As in ex. (a) of fn. 13; or in exx. 14 and 21. 
mechanism available for next-speaker selection which can prefer, formally, a next speaker identified only in turn-taking terms (and thus context-free terms) is one which selects prior speaker as next speaker.

(c) The technique described under (a) above, the use of a first pair-part addressed, might appear to constrain sharply the talk of a turn in which a 'current selects next' technique was to be used. That is, it might appear that any such turn would have to be constructed as a first pair-part; and 'current selects next' techniques would then seem to have no general operability, but be tied to utterances constructed as first pair-parts. It should, therefore, be noted that a turn's talk, whether or not it initially be constructed as a first pair-part, can be made into a locus of 'current selects next' by the affiliation to it of a 'tag question', e.g. You know?, Don't you agree?, etc.

The availability of the 'tag question' as affiliable to a turn's talk is of special importance, for it is the generally available 'exit technique' for a turn. That is, when a current speaker has constructed a turn's talk to a possible transitionrelevance place without having selected a next, and he finds no other self-selecting to be next, he may, employing his option to continue, add a tag question, selecting another as next speaker upon the tag question's completion, and thereby exiting from the turn. In this regard, the tag question is one member of a class we may call 'recompleters', a class that supplies one major source of the talk done when rule 1c's option is exercised. The effectiveness of tag questions in this regard is that they invoke rule 1a, making the start of a particular next speaker's turn relevant on THEIR completion. It should be noted that such use of rule la via tag questions is sequentially quite different from the invocation of rule 1a via turns constructed from their starts to be, e.g., adircsied questions: the former are instances where rule $1 \mathrm{a}$ is applied only when rule $1 \mathrm{~b}$ has not been exercised. While turns that employ rule la's option from their starts thus project turn-transfer at first transition-relevance place, tag questions (i.e., what we might term ' $1 \mathrm{c}-1 \mathrm{a}$ 's) come after an initial transition-relevance place. They thus operate in a second cycle of the ruleset's options.

(d) The list of 'current speaker selects next' techniques can be extensively expanded by inclusion of techniques which employ social identities in their operation. Thus, in a conversation involving two couples, an invitation made by a speaker to go to the movies will be heard to select as next speaker a member of the 'other couple', excluding 'own spouse'. The problem of introducing particular social identities into our description of the technology is especially complex, because one of the major aspects of the flexibility of conversation is that it is compatible with multiplicities of, and changes in, the social identities of some 'same' participants. A formal characterization of how participants' social identities are made relevant, and changed in conversation, does not now exist, though work is proceeding on that problem. It is clear enough that some 'current selects next' techniques are tied to the issue with which such a formal characterization will deal, but for now they are too cumbersome to be introduced in detail (cf. Sacks 1972).

(e) The basic technique for self-selection is 'starting first'. Rule 1b explicitly incorporates this in its provision that 'first starter gets the turn'. That formulation 
should not primarily be heard to refer to a circumstance in which, upon one turn's completion, several parties begin to talk, among whom 'first starter goes'. Rather it invites noting that regularly, after a very brief pause, only one starts. That is, inter-utterance pauses are very brief, which shows that one regularly starts fast; and the SINGLE starter should be thought of as 'first starter', succeeding in being single starter because of the 'first starter goes' provision, and being 'dispensable' in that, if he had not started fast, someone else would have. Here it is appropriate to recall the earlier discussion of the pressure rule $1 \mathrm{~b}$ and its 'first-starter' provision exert on turn size: the first-starter provision motivates any intending self-selector to start as early as possible at an earliest/next transition-relevance place; and a current speaker, oriented to that, will so construct a turn's talk as to allow its intact formation in the face of this pressure. Thus there is a pressure for turn-size minimization from both sides.

The pressure for early starts on self-selectors, produced by the 'first starter goes' provision, is constrained by a feature of the unit-types out of which a turn's talk is constructed. It was noted in $\$ 3.1$ that the unit-types project, from their beginnings, features of their construction, their direction, and what it will take to complete them. ${ }^{32}$ A self-selector aiming for an earliest start, one projected in the course of the ongoing utterance so as to fit closely to its completion, has the problem that his earliest start must begin with a unit-type's beginning-one which, given its projectability, will need to reflect some degree of planning for the turn's talk, and will itself project that planfulness. That will be involved, though current turn is still in progress, and may be internally extended with its extensions modifying its direction. There are, as well, the additions to prior turn mentioned in $\$ 4.3$, of articulatory extensions and optional post-completion elements after first possible transition place. A next-turn's beginning is thus subject to multiple sources of overlap, and an overlap of a unit-type's beginning may impair its part in the turn's utterance construction and its projection of the turn's plan. Therefore, the need to begin with a sentence's beginning (where a sentence is the planned unit) constrains the relative timing of its turn's start, for its analysability may be affected if it overlaps.

With regard to the 'begin with a beginning' constraint and its consequences, a familiar class of constructions is of particular interest. Appositional beginnings, e.g. well, but, and, so etc., are extraordinarily common, and do satisfy the constraints of beginning. But they do that without revealing much about the constructional features of the sentence thus begun, i.e. without requiring that the speaker have a plan in hand as a condition for starting. Furthermore, their overlap will not impair the constructional development or the analysability of the sentence they begin. Appositionals, then, are turn-entry devices or PRE-STARTS, as tag questions are exit devices or POST-COMPLETERS. Appositionals and tag questions are

${ }^{32}$ For example, one large group of turn-beginnings are sentence starts; all are informative to some degree about the character of the sentence or turn so begun, and some extremely so. Thus a turn's talk beginning with a wH-word powerfully projects the possible involvement of a 'question' character to that turn, with by now familiar consequences-e.g., that it will possibly select a next speaker, possibly select last speaker as next speaker, and (given the availability of the one-word question form) possibly effect a rapid turn-transfer. 
heavily used devices, though the basis for their use is by no means self-evident linguistically. We are proposing that they are to be understood as devices with important turn-organizational uses.

(f) While the basic technique for self-selection is 'starting first', and it is by virtue of its operation that regularly first starters are only starters, it is obvious enough that self-selection is done when another self-selector has already started, and that such self-selectors Do in fact start a turn's talk. Aside from the case of 'more than one at a time' which is produced by simultaneous starts of selfselectors aiming for earliest possible start, there are many instances of 'more than one at a time' where one clearly started first. There are, then, techniques for 'second starters' or 'subsequent starters'.

The first-starter provision for self-selection operates without respect to type of utterance. Second-starter techniques, and their efficacy in superseding the operation of the first-starter provision, are contingent on the type of utterance they can, from their starts, reveal themselves to be. We cannot here begin to detail the constraints under which second-starter supersession operates. We can, however, recall one basis for such a supersession which was discussed earlier. It was noted, in the discussion of turn-order bias, that prior speaker can systematically be selected to be next speaker, that techniques for accomplishing this are overtly directed to problems of understanding prior utterance, and that the basis is thus furnished for the possibility of colloquy. Now we can note that addressing problems of understanding in this way is a priority activity in conversation. When a self-selector's turn-beginning reveals his turn's talk to be prospectively addressed to a problem of understanding prior utterance, he may by virtue of that get the turn, even though at the turn-transfer another started before him, so that his start is second:

$$
\begin{aligned}
& \text { R: Hey::, the place looks different. } \\
& \text { F: Yea:: hh. } \\
\rightarrow & \text { K: Ya have to see all ou [ } \mathrm{r} \text { new-*" } \\
\text { It does?* } & \text { D: } \\
& \text { R: Oh yeah }
\end{aligned}
$$

Note that $D$ starts well after $\mathbf{K}$, and that $\mathrm{K}$ does not withdraw until enough of D's turn is out (here all of it) to exhibit that he is raising a problem of understanding.

4.13. Various turn-constructional units are employed for the production of the talk that occupies a turn. The turn-taking system we are describing is one for conversation, i.e. for talk in interaction. We have proposed that the allocation of turn-space is organized around the construction of talk IN the turns. That organization appears to key on one main feature of the construction of the talk in a turn-namely, that whatever the units employed for the construction, and whatever the theoretical language employed to describe them, they still have points of possible unit completion, points which are projectable before their occurrence. Since that is the better part of what the turn-taking system asks of the language materials from which its turns are fashioned, it will be compatible with a system of units which has this feature.

Our discussion in $\S 3.1$ of the turn-constructional component of the turn-taking system identifies the types of turn-constructional units as sentential, clausal, phrasal, and lexical-i.e. syntactically. The discussion of appositionals and tag 
questions-and, most importantly, the way in which the prospect of turn-transfer at the first possible transition-relevance place conditions decisions as between leftembedded and conjoined sentence structures-should indicate the deep ways in which syntax matters to turn-taking, albeit a syntax conceived in terms of its relevance to turn-taking. If one examines empirical materials to see where, in an ongoing turn, next speakers begin (or try to begin) next turns, one finds that such starts do not occur continuously over the developmental course of a turn, but discretely over its development. That is, possible transition-relevance places recur discretely in the course of a turn (this is the import of rule 2 in the rule-set). Examination of WHERE such 'next-turn starts' occur in current turns shows them to occur at 'possible completion points.' These turn out to be 'possible completion points' of sentences, clauses, phrases, and one-word constructions, ${ }^{33}$ and multiples thereof:

(24) Penny: An' the fact is I- is- I jus' thought it was so kind of stupid

Janet: $\quad\left[\begin{array}{l}\text { I didn' even say anything } \\ Y_{-}\end{array}\left[\begin{array}{l}\text { when I came ho: me. } \\ \text { Eh- }\end{array}\right.\right.$

Janet: Well Estelle jus' called 'n ...

[Trio: II]

(25) Tourist: Has the park cha:nged much,

Parky: Oh:: ye:s,

(1.0)

Old man: Th' Funfair changed it 'n [ahful lot [didn' it.

Parky: $\quad$ Th- That-

Parky: That changed it,

[T. Labov: Battersea:B:1]

(26) Ken: I saw 'em last night [at uhm school.

Jim: $\quad$ They're a riot

[GTS:5:9]

(27) Louise: I think it's really funny [to watch.

Roger: $\quad$ Ohhh God!

[GTS:1:mcl:7]

(28) A: Well we just wondered,

A: We just came in from Alexandria,

A: Just got home

A: and [these winds were so bad we're gettin scared again heh

B: $\quad$ Mm hm,

B: $\quad$ No, [we doh-

A: $\quad$ And we wondered whether we should go to a motel or something.

B: $\quad$ No, you stay right where you are ...

[CDHQ: 2: 82]

Note that, in 24-27, the next turn-starts come at first possible transition-places and next possible transition-places; in 28, A finishes a number of turn-constructional units before B comes in, A comes back in after a first-lexical-unit, and B comes back in at first possible completion of a first-sentential-unit. See also ex. 33, below.

The empirical materials of conversation, then, lead to the observation about the use of such components, and to their inclusion in the model of turn-taking as the elements out of which turns are built.

Clearly, in some understanding of 'sound production' (i.e. phonology, intonation etc.), it is also very important to turn-taking organization. For example, discriminations between what as a one-word question and as the start of a sentential (or

${ }^{33}$ See fn. 12 above. 
clausal or phrasal) construction are made not syntactically, but intonationally. When it is further realized that any word can be made into a 'one-word' unittype,$^{34}$ via intonation, then we can appreciate the partial character of the unittypes' description in syntactic terms.

While the rule-set itself appears to treat as central only the 'projectable completion' feature of its host's language materials, it seems productive to assume that, given conversation as a major, if not THE major, locus of a language's use, other aspects of language structure will be designed for conversational use and, pari passu, for turn-taking contingencies. The interaction of syntactic and turn-taking structures, however, awaits serious investigation, perhaps along lines such as the following.

We earlier noted that the turn-taking system is one for sequences of turns. A turn is to be thought of as a 'turn-in-a-series', with the potential of the series being made into a sequence. Turns display gross organizational features that reflect their occurrence in a series. They regularly have a three-part structure: one which addresses the relation of a turn to a prior, one involved with what is occupying the turn, and one which addresses the relation of the turn to a succeeding one. These parts regularly occur in that order, an obviously rational ordering for an organization that latches a turn to the turns on either side of it:

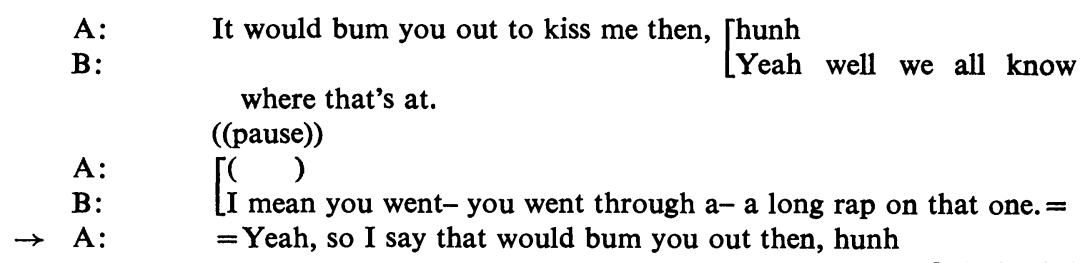

[TZ:21-23]

Here 'yeah' is a formal affiliator to last turn; 'hunh' is a tag question, projecting a link to next turn.

(30) D: Jude loves olives.

J: That's not bad.

$\rightarrow$ D: $\quad$ She eats them all the time. I understand they're fattening, huh ?

[Fat tape: 1]

Here the first sentence relates to a prior via multiple pro-term use, and a tag question projects a link to next turn.

(31) J: But by the time you get out of the shower and get your d- self

$\rightarrow$ M: $\quad\left[\begin{array}{l}\text { ready, } \\ \text { Well I'm not ready. I haven't kept you waiting yet though, have I? }\end{array}\right.$

J: Michael, you will, I know you will [Fat tape: 6]

Here the first sentence relates to the prior, at least by contrast, and the tag question relates to a next.

(32) B: Maybelle's takin' this week off, and she- you know something, she looked kinda tired.

$\rightarrow$ A: $\quad$ Uh huh. (2.0) Uhm well I guess she's been working pretty steadily,

B. $\quad\left[\begin{array}{l}\text { hasn't she. } \\ \text { Yeah, she's been workin pretty steady, and she's had some difficult }\end{array}\right.$ cases.

[Ladies:12:13]

${ }^{34}$ See $\$ 4.12$, point (b), re 'partial repeats' and the citation there. 


$\begin{array}{ll}\text { N: } & \text { Yah an' an' the fact that you're you feel guilty about eating them } \\ \text { that's what makes you break out, because it's- it's all inside you. } \\ \text { H: So people who've broken out they're just very emotional } \\ \text { H: } \\ \text { N: } & \text { [people, huh, } \\ \text { Heh heh heh, and they're worried [about it. } \\ \text { H: } \\ \text { N: } \\ \text { H: I don't know. It sounds kinda crazy, bu:t }\end{array}$

The turn-taking system, it should by now be clear, exerts pressure for these systematically potential turn-parts, or turn-jobs, to be accomplished before first possible completion, e.g. in a single sentence:

(34) A:

So it could happen to:: some people. 'hh But I: I wouldn' uh I wouldn': I wou- I say I wouldn' uh ((pause)) I don' know of anybody- that- 'cause anybody that I really didn't di:g I wouldn't have the ti:me, uh: a:n: to waste I would say, unh if I didn' [C

$\rightarrow \mathbf{B}:$

And you consider it wasting to jist be- you know- to jist like talkin' an' bein' with somebody.

A: $\quad$ Yeah. If you haven't got nothin' goin' (you're) jist wastin' your time. 'hh You could be doin' somethin' important to you. You know an- =

[TZ:57-59]

Here $B$ links to a prior turn via the conjunction and the cross reference, and links to a next by building the turn as a first part of an adjacency pair, confirmationrequest/confirmation, getting a confirmation next.

$\mathrm{N}: \quad$ So [what ti*me-
$\mathrm{H}: \quad$ Now what-*
$\mathrm{N}: \quad$ Oh so we we get the tickets when we get there, [right?
$\mathrm{H}: \quad$ reserved seats.
Here the interruption marker 'oh' exhibits a relationship to prior, and the tag
[HG:3]
question to next. See also ex. 33, second turn, which is similar to 34.

It is expectable, then, that some aspects of the syntax of a sentence will be best understood by reference to the jobs that need to be done in a turn-in-a-series, turns being a fundamental place for the occurrence of sentences.

4.14. Repair mechanisms exist for dealing with turn-taking errors and violations. The various organizations operative in conversation are susceptible to errors, violations, and troubles; and repair devices are available for them. We cannot here enter into a full discussion of repair ${ }^{35}$ instead, we mean to touch on three themes.

First, among the variety of repair devices are ones directed to, and designed for, turn-taking problems. No special theoretical motivation is needed to observe that questions such as Who me?,36 the lore and practices of etiquette concerning

${ }^{35}$ For discussion of two different aspects of repair, cf. Jefferson 1972, Sacks \& Schegloff 1974.

${ }^{36}$ An example is: Mother, 11-year-old daughter, and dog are in bed; the daughter is going to sleep; the dog has been addressed earlier in the conversation.

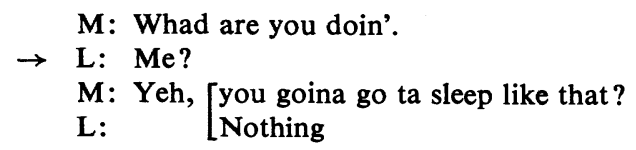


'interruption' and complaints about it, the use of interruption markers such as Excuse me and others, false starts, repeats or recycles of parts of a turn overlapped by others-as well as premature stopping (i.e. before possible completion) by parties to simultaneous talk-are repair devices dirscted to troubles in the organization and distribution of turns to talk.

Second, at least some of the mechanisms for turn-taking repair are intrinsic to the very system whose troubles they repair. Thus the basic device for repairing 'more than one at a time' involves a procedure which is itself otherwise violative in turntaking terms, namely stopping a turn before its possible completion point (e.g., ex. 23); it involves, then, a transformation of a central feature of the turn-taking system-the use of turn-constructional units to their next possible completionand not some device external to it. In that regard, we can further note that there are places in the rule-set itself designed for repair, in particular the cycle of options provided by rules $1 \mathrm{~b}$ and $1 \mathrm{c}$. What we earlier ( $\$ 4.12$, point (c)) called ' $1 \mathrm{c}-1 \mathrm{a}$ 's, a current-speaker continuation after the non-occurrence of turn-transfer at a transition-relevance place-a continuation which selects a next speaker to goshould be appreciated as repairing a failure of turn-transfer, provision for which is directly incorporated in the turn-taking system's basic organization. A major feature of a rational organization for behavior which accommodates real-world interests, and is not susceptible of external enforcement, is that it incorporates resources and procedures for repair into its fundamental organization.

Third, the turn-taking system constrains repairs of other than a turn-taking sort. For example, repairs by other than current speaker are not done until a turn's completion, respecting the turn-taking system's allocation of rights to a turn even where repair is found necessary. In fact, most repair (e.g. correction of a word) is done within the turn in which the repairable occurs. But when repair spills over the boundaries of a turn, as when other-than-speaker initiates a repair in the turn following the one in which the repairable occurred, then the sequence so initiated is organized by the same turn-taking system, and the repair sequences exhibit the same features of turn-taking as we have been discussing, including the feature currently under discussion: i.e., repair sequences can take repair. ${ }^{37}$

The compatibility of the model of turn-taking with the facts of repair is thus of a dual character: the turn-taking system lends itself to, and incorporates devices for, repair of its troubles; and the turn-taking system is a basic organizational device for the repair of any other troubles in conversation. The turn-taking system and the organization of repair are thus 'made for each other' in a double sense.

5. THE TYPE OF MODEL THIS Is. So far, we have touched on a variety of literature in which materials relevant to turn-taking organization in conversation are collected, addressed, or analysed, although not necessarily in explicitly turn-taking terms; we have proposed a set of grossly observable features of conversation with

L: No, hh heh hh hh

M: With your rear end sticking up in the air, how you gonna sleep like that.

L: heh heh I'm n(h)ot(h)

[L\&M:7]

${ }^{37}$ Earlier work on repair (e.g., Jefferson 1972, Schegloff 1972, Sacks \& Schegloff 1974) encountered the ordering of repair by the turn-taking system, without having especially looked for it. Note in particular the data in Jefferson 1972 with regard to the present discussion. 
which a model of turn-taking should come to terms, if it is to merit serious consideration; we have proposed a model of a turn-taking system for conversation, or at least some major components of such a model; and we have sketched how that model comes to terms with the facts we had proposed as constraints. Hopefully, in the course of the discussion, we have displayed some interesting features and uses of that model. It is certainly the case that the proposed model is in several respects incorrect or insufficient. But however this particular model may be defective, we believe our discussions support the claim that the appropriate model for turn-taking in conversation will be this SORT of model. In the present section, try to characterize what that 'sort' is, by citing a few of its most important features we with some elaborations. Those features are that it is a LOCAL MANAGEMENT SYSTEM, and that it is an INTERACTIONALLY MANAGED SYSTEM. After characterizing the sort of system it is, we will offer a formulation of the sort of problem it seems designed to solve.

In characterizing the turn-taking system with which we have been dealing as a 'local management system', we note the following clear features of the rule-set and the components:

(1) The system deals with single transitions at a time, and thereby with only the two turns which a single transition links; i.e., it allocates but a single turn at a time.

(2) The single turn it allocates on each occasion of its operation is 'next turn'.

(3) While the system deals with but a single transition at a time, it deals with transitions:

(a) comprehensively-i.e., it deals with any of the transition possibilities whose use it organizes;

(b) exclusively-i.e., no other system can organize transitions independent of the turn-taking system $;^{38}$ and

(c) serially, in the order that they come up-via its dealing with 'next turn'.

These features by themselves invite a characterization of the system of which they are part as a local management system, in that all the operations are 'local', i.e. directed to 'next turn' and 'next transition' on a turn-by-turn basis. It should be noted that this much constitutes local management only with respect to turn-order: the system is, however, locally managed with respect to turn-size as well. Not only is the allocation of turns accomplished in each turn for a next, but the determination of turn-size is accomplished locally, i.e. in the developmental course of each turn, under constraints imposed by a next turn, and by an orientation to a next turn in the current one. Our earlier discussion pointed out a range of features in conversation that are not fixed, but vary; however, the two that the system directly and explicitly concerns itself with in its machinery are turn-size and turn-order. The turn-taking system is a local management system, then, in the sense that it operates in such a way as to allow turn-size and turn-order to vary and be under local management, across variations in other parameters, while still achieving both the

${ }^{38}$ Thus, while an addressed question requires an answer from the addressed party, it is the turn-taking system, rather than syntactic or semantic features of the 'question', that requires the answer to come 'next'. 
aim of all turn-taking systems-the organization of ' $n$ at a time'-and the aim of all turn-taking organizations for speech-exchange systems-'one at a time while speaker change recurs' (cf. Miller 1963:418).

The turn-taking system under examination can be further characterized for the kind of local management system it is. The character and organization of the rules that constitute it as a local management system themselves determine its more particular organization in not only allowing and/or requiring turn-size and turnorder to vary, but in subjecting their variability to the control of the parties to any conversation. It is, therefore, among local management systems, a 'party-administered' system. Furthermore, it makes turn-size and turn-order interdependent by interlocking the mechanisms for their respective determinationturn-allocation mechanisms having consequences for turn-size, and procedures for regulating or determining turn-size employing turn-allocation techniques (as in the use of tag questions as turn-exits and therefore turn-stopping devices). The system then integrates the machinery for turn-size and turn-order organization, and subjects that machinery to the administration of the parties to any conversation. The mechanism by which the system lends itself to party administration, by which turn-size and turn-order determinations are integrated, and by which the system achieves comprehensiveness for any turn-transition, is the option-cycle provided by the ordered set of rules. That rule-set provides options for 'speakers' and 'potential next speakers', putting itself thereby at the disposal of participants; it interconnects 'stopping by current' and 'starting by next', thereby connecting turn-size with turn-order; and it is abstractly formulated, so as to not exclude any transition place from its scope.

Further features of the system, collected under the rubric 'interactionally managed', deal with the way in which the turn-taking system, in its local-management, participant-administered form, fits to conversational interaction, and is a specific adaptation of turn-taking for it.

Party administration need not be interactive. In the turn-taking system for conversation, however, it is. The party-administered, local management of turnorder is effected through the rule-set, whose ordered property provides a cycle of options in which any party's contribution to turn-order determination is contingent on, and oriented to, the contributions of other parties. The basis of this contingency is given by the ways in which the operation of any of the options provided by the rules is contingent on higher-order options not having been exercised, and constrained by the prospective operation of lower-order options (a point discussed in \$3.4).

Turn-size is also the product not only of party-administered local management, but of interactional production. That involves the sort of turn-unit used by the turn-taking system, a facet which can here be used to explicate further what we mean in characterizing the system as 'interactionally managed'. The turn-unit is of a sort which (a) employs a specification of minimal sizes, but (b) provides for expansion within a unit, (c) is stoppable (though not at any point), and (d) has transition places discretely recurring within it, (e) which can themselves be expanded or contracted; all of these features except the first are loci of interactional determination. By virtue of this character, it is misconceived to treat 
turns as units characterized by a division of labor in which the speaker determines the unit and its boundaries, with other parties having as their task the recognition of them. Rather, the turn is a unit whose constitution and boundaries involve such a distribution of tasks as we have noted: that a speaker can talk in such a way as to permit projection of possible completion to be made from his talk, from its start, allowing others to use its transition places to start talk, to pass up talk, to affect directions of talk etc.; and that their starting to talk, if properly placed, can determine where he ought to stop talk. That is, the turn as a unit is interactively determined. ${ }^{39}$

For conversationalists, the facts that turn-size and turn-order are locally managed, party-administered, and interactionally controlled means that these facets of conversation, and those deriving from them, can be brought under the jurisdiction of perhaps the most general principle which particularizes conversational interactions, that of RECIPIENT DESIGN. ${ }^{40} \mathrm{By}$ 'recipient design' we refer to a multitude of respects in which the talk by a party in a conversation is constructed or designed in ways which display an orientation and sensitivity to the particular other(s) who are the co-participants. In our work, we have found recipient design to operate with regard to word selection, topic selection, admissibility and ordering of sequences, options and obligations for starting and terminating conversations, etc., as will be reported in future publications. ${ }^{41}$ Recipient design is a major basis for that variability of actual conversations glossed by the notion 'contextsensitive'. In referring to the particularizing operation of recipient design on turnsize and turn-order, we are noting that parties have ways of individualizing some 'this conversation'; their collaboration in turn-allocation and turn-construction achieves a particular ordering of particular-sized turns and turn-transition characteristics of the particular conversation at a particular point in it. ${ }^{42}$ In evolving a machinery by which turn-organization is subjected to recipient design in a workable way, turn-taking, abstractly conceived, is adapted specifically for conversation.

6. SOME CONSEQUENCES OF THE MODEL. In this section, we hope to state briefly some consequences of the type of organization we have described. We will consider only such sorts of consequences as are of 'general interest'.

6.1. An intrinsic motivation is identifiable for listening. In its turn-allocational techniques, the turn-taking system for conversation builds in an intrinsic motivation for listening to all utterances in a conversation, independent of other possible motivations, such as interest and politeness. In the variety of techniques for arriving at a next speaker, and in their ordered character, it obliges any willing or potentially intending speaker to listen to and analyse each utterance across its delivery. Thus a participant, willing to speak next if selected to do so, will need to

${ }^{39}$ Prior researchers, e.g., Bales 1950 and Jaffe \& Feldstein 1970, in looking for a unit that could be 'recognized' (possibly for good technical reasons for their research), have focused on its self-determined, independent, recognizable completeness. This appears to contrast with the main turn-organizational character of conversation, which is the interactional shaping of turns.

${ }^{40}$ We owe the possibility of ever having seen the importance of the particularization theme to our acquaintance with Harold Garfinkel; cf. his works of 1967 and 1970.

${ }^{41}$ Regarding word selection, cf. Sacks \& Schegloff.

${ }^{42}$ Cf. Jefferson 1973: 56-71, et passim. 
listen to each utterance and analyse it at least to find whether or not it selects him as next speaker. And any potentially intending speaker will have to listen to any utterance after which he might want to speak, to find, at least, that no other has been selected as next speaker. Under either of these circumstances, a willing or potentially intending next speaker will have to listen through the end of the current utterance in order to effect turn-transfer properly, and perhaps in order to secure the turn. Given the mechanism for selecting 'last speaker as next', a current speaker will also be subject to this motivation upon completion of his turn. By maximizing the set of potential next speakers for any next turn (cf. \$4.9), the system translates a willingness or potential desire to speak into a corollary obligation to listen.

6.2. Turn-taking organization at least partially controls the understanding of utterances. There are a variety of candidate proposals with regard to the question of how talk is understood. The investigation of turn-taking contributes to this problem in various ways. Thus, the basis furnished by the turn-taking system for listening, just discussed, may be amplified in the following respect. A participant potentially willing to speak if selected to do so will need to listen to any utterance to find if he is being selected by it to speak next. Since a major class of 'current selects next' techniques is constituted by 'first pair-parts'-i.e. by type-characterized utterances such as 'greeting', 'question', 'insult', 'complaint' etc.-a willing speaker will need to analyse utterances to find if an instance of such an utterancetype is being employed, and in a way that possibly selects him as next speaker. And a potentially intending speaker will need to examine any utterance after which he might want to speak, to find whether such a thing was being done to him or to some other party.

6.3. The turn-taking system has, as a by-product of its design, a proof procedure for the analysis of turns. When A addresses a first pair-part such as a 'question' or a 'complaint' to B, we have noted, A selects B as next speaker, and selects for B that he next perform a second part for the 'adjacency pair' $A$ has started, i.e. an 'answer' or an 'apology' (among other possibilities) respectively. B, in so doing, not only performs that utterance-type, but thereby displays (in the first place to his co-participants) his understanding of the prior turn's talk as a first part, as a 'question' or 'complaint'.

Herein lies a central methodological resource for the investigation of conversation (by contrast with the investigation of literary and other 'text' materials), a resource provided by the thoroughly interactional character of conversation. It is a systematic consequence of the turn-taking organization of conversation that it obliges its participants to display to each other, in a turn's talk, their understanding of other turns' talk. More generally, a turn's talk will be heard as directed to a prior turn's talk, unless special techniques are used to locate some other talk to which it is directed. Regularly, then, a turn's talk will display its speaker's understanding of a prior turn's talk, and whatever other talk it marks itself as directed to (cf. Moerman \& Sacks, MS).

In the first place, of course, such understandings are displayed to co-participants, and are an important basis for the local self-correction mechanism of conversation. Clearly, they also supply another important basis for the 'last as next' turn-order 
bias, a prior speaker being motivated to self-select as next speaker if he finds the understanding of his prior utterance, displayed by current speaker in current turn, unacceptable.

But while understandings of other turns' talk are displayed to co-participants, they are available as well to professional analysts, who are thereby afforded a proof criterion (and a search procedure) for the analysis of what a turn's talk is occupied with. Since it is the parties' understandings of prior turns' talk that is relevant to their construction of next turns, it is THEIR understandings that are wanted for analysis. The display of those understandings in the talk of subsequent turns affords both a resource for the analysis of prior turns and a proof procedure for professional analyses of prior turns-resources intrinsic to the data themselves.

7. The Place of CONVERSATION AMONG THE SPEECH-EXCHANGE SYSTEMS. The use of a turn-taking system to preserve one party talking at a time while speaker change recurs, for interactions in which talk is organizationally involved, is not at all unique to conversation. It is massively present for ceremonies, debates, meetings, press conferences, seminars, therapy sessions, interviews, trials etc. All these differ from conversation (and from each other) on a range of other turn-taking parameters, and in the organization by which they achieve the set of parameter values whose presence they organize. ${ }^{43}$

Such a sort of comparative investigation of the speech-exchange systems available to members of a single society, conceived of in terms of differential turn-taking systems, has barely been looked into by us. However, certain striking arrangements may be noted, if only to suggest the possible interest of this area.

It seems, as noted, correct to say that generally the allocational techniques for conversation provide for one turn-allocation at a time. But alternatives to such a mode of operation are readily found. Thus, in debates, the ordering of all turns is pre-allocated, by formula, with reference to 'pro' and 'con' positions. In contrast to both debates and conversation, meetings with chair-persons partially pre-allocate turns, and provide for the allocation of unallocated turns via the use of the preallocated turns. Thus, chair-persons have rights to talk first, and to talk after each other speaker, and they can use each such turn to allocate next-speakership.

The foregoing suffices to suggest a structural possibility: that turn-taking systems, or at least the class of them whose members each preserve 'one party talks at a time', are, with respect to their allocational arrangements, linearly arrayed. The linear array is one in which one polar type (exemplified by conversation) involves 'one-turn-at-a-time' allocation, i.e. the use of local allocational means; the other pole (exemplified by debate) involves pre-allocation of all turns; and medial types (exemplified by meetings) involve various mixes of pre-allocational and localallocational means.

That the types can be so arrayed permits them to be compared, directly, in relevant functional terms. Thus one pole (local allocation of turns) permits maximization of the size of the set of potential speakers to each next turn, but is not

${ }^{43}$ Nor is the feature unique to a particular linguistic or social community. It is evidently exhibited in conversation, meetings, etc. in societies whose languages and systems of social organization differ quite drastically. Cf., e.g., Albert, and fn. 10 above. 
designed organizationally to permit the methodical achievement of an equalization of turns among potential speakers; whereas the other pole (pre-allocation of all turns) is designed to permit the equalization of turns (or can be-it can be designed for other ends), which it does by specifying next speaker, thereby minimizing the size of the set of potential next speakers. If the range of turn-taking systems is arrayed on a continuum, ranging from full pre-allocation of turns to single allocation at a time, then any system may be found to maximize, minimize, or not be organizationally relevant to a range of functions such as equalization of turns among participants, maximization of potential next speakers, etc. The functions for which any system is design-relevant may then be explored; and the various systems may be compared with respect to their consequences on any given function of interest. On the two functions we have mentioned, equalization of turns and maximization of the set of next-speaker candidates, local allocation and full pre-allocation are polar types-as indeed they might turn out to be for any function where turn-allocation is systematically relevant.

Given the linear array, the polar position of conversation, and the functions of which that position permits maximization, a characterization of the organization of turn-taking in conversation takes on more than merely ethnographic interest. Occupying such a functionally interesting structural position, conversation is at least a representative of the means by which one polar possibility is organizationally achieved.

All positions on the linear array use turns, and preserve the feature 'one party talks at a time'. While they each specify these differently, and while our systematic characterization has been for conversation only, one further generalization-and the orderliness of the difference which it leads to noting-may be mentioned. For all positions of the linear array, 'turns' are at least partially organized via languagespecific constructional formats, e.g. syntactic construction (of which sentential construction is a most important and familiar, but not sole, instance). Turn-size may be characterizable by two different aspects of sentential organization: (a) multiplication of sentence units in a turn, and (b) increasing complexity of syntactic construction within single sentence units. Two observations can be made about turn-size and its relation to position on the linear array. First, turn-size increases with increasing degrees of pre-allocation on the linear array. Second, the metric employed for gauging and for constructionally increasing turn-size may shift with position on the array: multiplication of sentence units is the central mode for the pre-allocational pole, and increasing internal complexity within single (or minimized) sentence units is the central mode for local-allocational systems. Both of these observations can be seen to be natural products of the design of the turntaking systems at various points on the array.

While we have referred to conversation as 'one polar extreme' on the linear array, and 'ceremony' as possibly the other pole, we should not be understood as proposing the independent or equal status of conversation and ceremony as polar types. It appears likely that conversation should be considered the basic form of speech-exchange system, with other systems on the array representing a variety of transformations of conversation's turn-taking system, to achieve other types of turn-taking systems. In this light, debate or ceremony would not be an independent 
polar type, but rather the most extreme transformation of conversation-most extreme in fully fixing the most important (and perhaps nearly all) of the parameters which conversation allows to vary.

\section{APPENDIX: CONVENTIONS USED IN TRANSCRIPTS}

SEQUENCING. The transcription of sequential features is done with special care, using the following conventions:

The double oblique $(/ /)$ indicates the point at which a current speaker's talk is overlapped by the talk of another:

V: Th' guy says tuh me- 'hh my son // didid.

M: Wuhjeh do:.

A multiple-overlapped utterance is followed, in serial order, by the talk which overlaps it. Thus C's 'Vi:c' occurs simultaneously with V's 'left', and her 'Victuh' occurs simultaneously with his 'hallway':

V: I // left my garbage pail in iz // hallway.

C: Vi:c,

C: Victuh,

An alternate system is to place a single bracket at the point of overlap, and place the overlapping talk directly beneath the talk it overlaps:

V: Th' guy says tuh me- 'hh my son [didid.

M: $\quad$ Wuhjeh do:.

In front of two serially transcribed utterances, the bracket indicates that they start simultaneously:

M: I mean no no n'no.

V: [P't it back up,

A single right-hand bracket indicates the point at which two overlapping or simultaneouslystarted utterances end, if they end simultaneously, or the point at which one of them ends in the course of another, or the point at which one utterance-component ends vis-à-vis another. In some data cited in this paper, an asterisk is used instead:

M: [I mean no no n'no.]

V: [P't it back up,]

M: Jim // wasn' home] uh what.

V: $Y^{\prime}$ kno: $w$ ?]

M: Jim // wasn' home* uh what.

$\mathrm{V}$ : Y'kno:w?*

In general, the equals sign $(=)$ indicates 'latching'-i.e., no interval between the end of a prior and start of a next piece of talk. It is used for the relationship of a next speaker's talk to a prior speaker's, for the relationship of two parts of a same speaker's talk, and as a transcript convenience for managing long utterances which are overlapped at various points, in which case a through-produced utterance may be more or less arbitrarily broken up:

R: Wuhjeh do:: $=$

V: = I said did, he, get, hurt.

V: My wife // caught d' ki:d, =

R: Yeh.

V: =lightin' a fiyuh in Perry's celluh.

V: Well my son did it =I'm gladjer son didn' get hu:rt, 'hh I said but ...

An equals sign at the end of one speaker's utterance, followed by the equals sign combined with a left-hand bracket, indicates that the bracketed speakers have started simultaneously, with 
no interval after the preceding talk. This may occur for a speaker followed by two others, or for one 'continuing' speaker and one other:

J: The son of a bitch gottiz // neck cut off. Dass wuhd 'e should of did, =

V: Wuh-

V: $=$ I'm not intuh this.

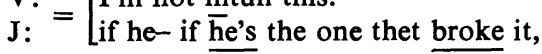

An alternate system is to place double obliques in the course of what is treated as a single ongoing utterance by a first speaker:

J: ... Dass wuhd 'e should of did, // if he- if he's the one thet broke it,

$\mathrm{V}$ : I'm not intuh this.

A right-hand bracket plus equal sign indicates that two utterances have ended simultaneously and will be 'latched' onto by a next. In this case, the two priors are latched onto by two simultaneously-starting nexts:

V: Ya:h, well I woulda picked it up.

M: [I mean no no n'no.]=

V: [P't it back up,] =

M: [Ih doesn' make any-]=

$\mathrm{V}:=$ [t doesn' mattuh.] =

M: If it breaks]

V: So dih gu:y] says 'hh

Numbers in parentheses indicate elapsed time in tenths of seconds. The device is used between utterances of adjacent speakers, between two separable parts of a single speaker's talk, and between parts of a single speaker's internally organized utterance:

V: ... dih soopuh ul clean it up,

( ): hhehh

V: No kidding.

M: Yeh there's nothin the:re?

M: Quit hassling.

V: She's with somebody y' know 'hh ennuh, (0.7) she says Wo:w ...

The long dash, rarely used in this paper, indicates an untimed pause, e.g. a 'beat':

$\mathrm{V}$ : I'm intuh my thing, intuh my:: - attitude against othuh pih- 'hh

SOUND-PRODUCTION is neither conscientiously nor consistently attended in the present data, but the following special symbols are used:

Punctuation markers are not used as grammatical symbols, but for intonation. Thus a question may be constructed with 'comma' or 'period' intonation, and 'question' intonation may occur in association with non-questions:

V: Becuss the soopuh dint pudda bu:lb on dih sekkin flaw en its burnt ou:t ?

V: A do: $g$ ? enna cat is diffrent.

R: Wuhjeh do:.

Colon(s) indicate that the prior syllable is prolonged. Multiple colons indicate a more prolonged syllable, as in the second example, in which V's 'Wow' covers five syllables in M's overlapped utterrace:

V: So dih gu: y sez 'hh

M: Yeh it's all in the chair all th//at junk is in the chair.]=

V: Wo:::::::w] $=$

$\mathrm{V}:=\mathrm{I}$ didn' know tha: $\mathrm{t}$ ? 
Underscoring indicates various forms of stressing, and may involve pitch and/or volume:

V: I sez y' know why, becawss look.

The relationship between stress and prolongation markers indicates pitch change (or nonchange) in the course of a word. In the first sentence, with stress marked only under the first letter, pitch does not change. In the second sentence, pitch drops at the end of 'ha: rd'; in the third, it rises at the end of 'ha:rd?'

$\mathrm{V}$ : 'M not saying he works ha:rd.

V: I don't work ha:rd.

$\mathrm{H}$ : Does he work ha: rd?

The short dash indicates a 'cut off' of the prior word or sound:

V: He said- yihknow, I get- I get sick behind it.

The $h$, within parentheses, within a word or sound, indicates explosive aspiration, e.g. laughter, breathlessness, etc.:

M: I'd a' cracked up 'f duh friggin (gla-i(h)f y' kno(h)w it) sm(h)a(h) heh heh

The $h$ without parentheses indicates audible breathing. A dot placed before it indicates an in-breath; no dot indicates out-breath:

V: So I sez, 'hh wa:1 whuddiyou goin do

The degree sign $\left({ }^{\circ}\right)$ indicates that the talk it precedes is low in volume:

$\mathrm{M}$ : Jim wasn' home, $/ /^{\circ}$ (when $\mathrm{y}^{\prime}$ wen over there)

Upper case indicates increased volume:

V: En it dint fall OUT!

READER's GUIDES. The following additional conventions should be noted:

Single pairs of parentheses indicate that transcribers are not sure about the words contained therein:

M: I'd a' cracked up 'f duh friggin (gla-i(h)f y' kno(h)w it) sm(h)a(h) heh heh

$\mathrm{M}$ : Jim wasn' home, $/ /^{\circ}$ (when $y^{\prime}$ wen over there)

Matched pairs of parentheses indicate not merely two possible hearings, but address the equivocality of each:

V: I'll be (right witchu.)

(back inna minnit.)

Empty parentheses indicate that no 'hearing' was achieved:

( ): Tch! ( )

On occasion, nonsense syllables are provided, in an attempt to capture something of the produced sounds:

$\mathrm{R}$ : ( $\mathrm{Y}^{\prime}$ cattuh moo?)

The speaker designation column is treated similarly: single parentheses indicate doubt about speaker, pairs indicate equivocal possibilities, and empties indicate no achieved identification of speaker.

Materials between double parentheses indicate features of the audio materials other than actual verbalization, or verbalizations which are not transcribed:

M: ((whispered)) (Now they're gonna, hack it.)

M: ((RAZZBERRY))

M: ((cough))

V: ((dumb-slob voice)) Well we usetuh do dis, en we use-

$\mathrm{J}$ : They're fulla sh::it.

Finally, it should be noted that the data excerpts cited in this paper are illustrative. They represent large collections of data on our various points, assembled 
out of a substantial number of conversations. The data cannot be presented more extensively because of space limitations, but all the data in the paper can be examined for points other than those in whose service they are initially cited, and in many cases we have selected such data excerpts for a point as would illustrate other points in the paper independently (arrows point to the location of the phenomenon for which the data excerpt is introduced). Similarly, all the data in all our other papers can be inspected for their bearing on the points made in this one. And any materials of natural conversation (transcribed to an appropriate level of detail and precision) collected by others may be examined as well. All this, of course, is appropriate if, indeed, what is proposed in the paper is so 'for any conversation'.

Some linguists have objected to our use of modified English spelling-rather than, say, IPA symbols: the result, they claim, resembles a sort of funnypaperEnglish, and could have derogatory connotations. Our reply is that we have simply tried to get as much of the actual sound as possible into our transcripts, while still making them accessible to linguistically unsophisticated readers; we certainly mean no disrespect to the parties cited.

\section{REFERENCES}

Albert, E. 1964. 'Rhetoric', 'logic', and 'poetics' in Burundi: culture patterning of speech behavior. In Gumperz \& Hymes, 35-54.

Bales, R. F. 1950. Interaction process analysis. Cambridge, Mass.: Addison Wesley.

- 1970. Personality and interpersonal behavior. New York: Holt, Rinehart \& Winston.

BARKer, R. G., and H. F. Wright. 1951. One boy's day. New York: Harper.

Beardsley, R. K; J. W. Hall; and R. E. Ward. 1959. Village Japan. Chicago: University of Chicago Press.

Beckett, S. 1972. The lost ones. New York: Grove Press.

Coleman, J. 1960. The mathematical study of small groups. Mathematical thinking in the measurement of behavior: small groups, utility, factor analysis, ed. by $\mathbf{H}$. Solomon, 7-149. Glencoe, Ill.: Free Press.

Duncan, S. D., JR. 1972a. Some signals and rules for taking speaking turns in conversations. Journal of Personality and Social Psychology 23.283-92.

- 1972b. Distribution of auditor back-channel behaviors in dyadic conversation. To appear in Journal of Psycholinguistic Research.

- 1973. Toward a grammar for dyadic conversation. Semiotica 9.29-46.

Garfinkel, H. 1967. Studies in ethnomethodology. Englewood Cliffs, N.J.: PrenticeHall.

- and H. SACKs. 1970. On formal structures of practical actions. Theoretical sociology, ed. by J. C. McKinney \& E. A. Tiryakian, 337-66. New York: AppletonCentury-Crofts.

GofFMAN, E. 1955. On face work: an analysis of ritual elements in social interaction. Psychiatry 18. 213-31.

- 1964. The neglected situation. In Gumperz \& Hymes, 133-6.

- 1971. Relations in public. New York: Basic Books.

GoldBERG, J. MS. A system for the transfer of instructions in natural settings. To appear in Semiotica.

Gumperz, J. J., and D. Hymes (eds.) 1964. The ethnography of communication. American Anthropologist 66:6, part 2 (special publication). Menasha, Wisc. 
ISAACS, S. 1933. Social development in young children. New York: Harcourt Brace. JAfFe, J., and Feldstein, S. 1970. Rhythms of dialogue. New York: Academic Press. JEFFERSON, G. 1972. Side sequences. In Sudnow, 294-338.

- 1973. A case of precision timing in ordinary conversation: overlapped tagpositioned address terms in closing sequences. Semiotica 9.47-96.

- and J. SCHENKEIN. MS. Some sequential negotiations in conversation: unexpanded and expanded versions of projected action sequences. To appear in Schenkein et al.

Jordan, B., and N. Fuller. MS. The non-fatal nature of trouble: sense-making and trouble managing in lingua franca talk. To appear in Semiotica.

Kendon, A. 1967. Some functions of gaze direction in social interaction. Acta Psychologica 26.1-47.

Matarazzo, J., and A. Wiens. 1972. The interview: research on its anatomy and structure. Chicago: Aldine-Atherton.

MilleR, G. 1963. Review of Universals of language, ed. by J. Greenberg. Contemporary Psychology 8.417-18.

Mitchell, J. C. 1956. The Yao village. Manchester: University Press.

Motrman, M. 1972. Analysis of Lue conversation: providing accounts, finding breaches, and taking sides. In Sudnow, 170-228.

- , and H. SACKS. MS. On understanding in conversation.

SACKs, H. 1972. An initial investigation of the usability of conversational data for doing sociology. In Sudnow, 31-74.

1974. An analysis of the course of a joke's telling in conversation. To appear in Explorations in the ethnography of speaking, ed. by J. Sherzer \& D. Baumann. Cambridge: University Press.

persons in conversation and their interaction. To appear in Ethnomethodology, labelling theory, and deviant behavior, ed. by N. H. Avison \& R. J. Wilson. London: Routledge \& Kegan Paul.

SCHEGLOFF, E. 1968. Sequencing in conversational openings. American Anthropologist 70.1075-95.

- 1972. Notes on a conversational practice: formulating place. In Sudnow, 75-119.

- MS. On some questions and ambiguities in conversation. In Schenkein et al.

- , and H. SACKS. 1973. Opening up closings. Semiotica 8.289-327.

SCHENKEIN, J.; F. SACK ; and E. WeINGARTEN (eds.) MS. Issues in conversational analysis. Berlin: Suhrkamp Verlag (to appear).

Stephan, F. F., and E. G. Mishler. 1952. The distribution of participation in small groups: an exponential approximation. American Sociological Review 17.598-608.

Sudnow, D. N. (ed.) 1972. Studies in social interaction. New York: Free Press.

YNGVE, V. 1970. On getting a word in edgewise. Papers from the 6th Regional Meeting, Chicago Linguistic Society, 567-77.

[Received 1 May 1974.] 